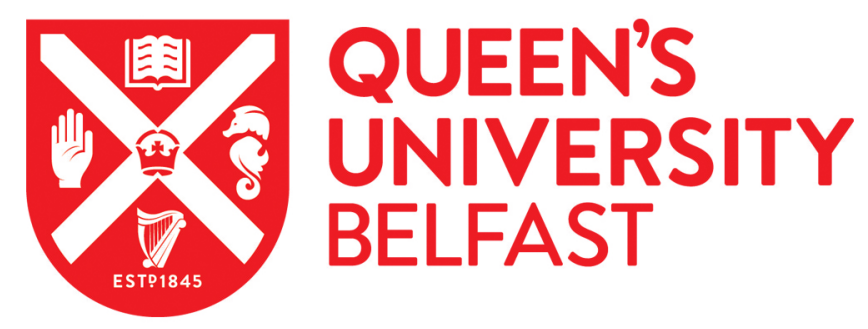

\title{
Insight into the Hydration of Cationic Surfactants: A Thermodynamic and Dielectric Study of Functionalized Quaternary Ammonium Chlorides
}

Medoš, Ž., Plechkova, N. V., Friesen, S., Buchner, R., \& Bešter-Rogač, M. (2019). Insight into the Hydration of Cationic Surfactants: A Thermodynamic and Dielectric Study of Functionalized Quaternary Ammonium Chlorides. Langmuir, 35(10), 3759-3772. https://doi.org/10.1021/acs.langmuir.8b03993

Published in:

Langmuir

Document Version:

Publisher's PDF, also known as Version of record

Queen's University Belfast - Research Portal:

Link to publication record in Queen's University Belfast Research Portal

\section{Publisher rights}

Copyright 2019 the authors.

This is an open access article published under a Creative Commons Attribution License (https://creativecommons.org/licenses/by/4.0/), which permits unrestricted use, distribution and reproduction in any medium, provided the author and source are cited.

\section{General rights}

Copyright for the publications made accessible via the Queen's University Belfast Research Portal is retained by the author(s) and / or other copyright owners and it is a condition of accessing these publications that users recognise and abide by the legal requirements associated with these rights.

Take down policy

The Research Portal is Queen's institutional repository that provides access to Queen's research output. Every effort has been made to ensure that content in the Research Portal does not infringe any person's rights, or applicable UK laws. If you discover content in the Research Portal that you believe breaches copyright or violates any law, please contact openaccess@qub.ac.uk. 


\section{Insight into the Hydration of Cationic Surfactants: A Thermodynamic and Dielectric Study of Functionalized Quaternary Ammonium Chlorides}

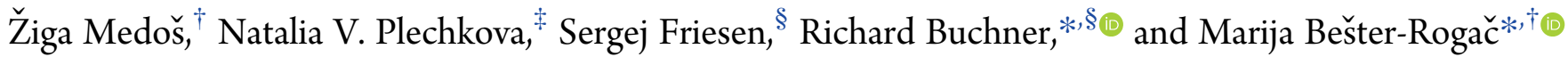

${ }^{\dagger}$ Faculty of Chemistry and Chemical Technology, University of Ljubljana, Večna pot 113, 1000 Ljubljana, Slovenia

${ }^{\ddagger}$ QUILL, The Queen's University of Belfast, Stranmillis Road, Belfast, Northern Ireland BT9 5AG, U.K.

${ }^{\S}$ Institut für Physikalische und Theoretische Chemie, Universität Regensburg, 93053 Regensburg, Germany

\section{Supporting Information}

ABSTRACT: Hydrophobic interactions are one of the main thermodynamic driving forces in self-assembly, folding, and association processes. To understand the dehydration-driven solvent exposure of hydrophobic surfaces, the micellization of functionalized decyldimethylammonium chlorides, $\mathrm{XC}_{10} \mathrm{Me}_{2} \mathrm{~N}^{+} \mathrm{Cl}^{-}$, with a polar functional group, $\mathrm{X}=\mathrm{C}_{2} \mathrm{OH}$, $\mathrm{C}_{2} \mathrm{OMe}, \mathrm{C}_{2} \mathrm{OC}_{2} \mathrm{OMe}, \mathrm{C}_{2} \mathrm{OOEt}$, together with the "reference" compound decyltrimethylammonium chloride, $\mathrm{C}_{10} \mathrm{Me}_{3} \mathrm{~N}^{+} \mathrm{Cl}^{-}$, was investigated in aqueous solution by density measurements, isothermal titration calorimetry (ITC), and dielectric relaxation spectroscopy (DRS). From the density data, the apparent molar volumes of monomers and micelles were

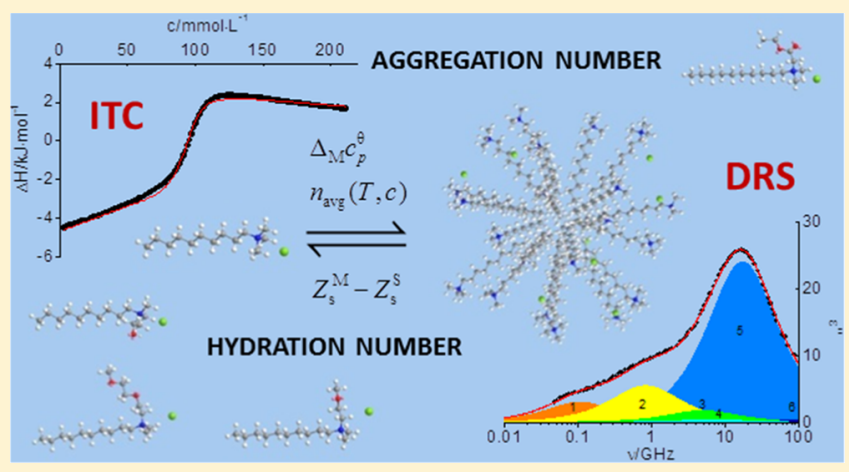
estimated, whereas the ITC data were analyzed with the help of a model equation, yielding the thermodynamic parameters and aggregation number. From the DRS spectra, effective hydration numbers of the free monomers and micelles were deduced. The comprehensive analysis of the obtained results shows that the thermodynamics of micellization are strongly affected by the nature of the functional group. Surprisingly, the hydration of micelles formed by surfactant cations with a single alkyl chain on quaternary ammonium is approximately the same, regardless of the alkyl chain length or functionalization of the headgroup. However, notable differences were found for the free monomers where increasing polarity lowers the effective hydration number.

\section{INTRODUCTION}

Hydrophobic and hydrophilic interactions are competing effects influencing the kinetics and dynamics of many processes in chemistry, biochemistry, and physics. The micellization of surfactants is regarded as a useful model process for their investigation. To understand these effects on a molecular level, recent studies attempted to explore the complete atomistic structure of a micelle and its surroundings in solution. ${ }^{1-3}$ It was found that the hydrophobic core of a micelle is surrounded by a highly corrugated surface containing hydrated nonpolar cavities, whose depth increases with increasing surfactant chain length. ${ }^{2}$ Additionally, the hydration behavior of the counterions has drastic effects on micelle size and shape. ${ }^{3}$

The aforementioned studies were carried out using quaternary ammonium salts with a long alkyl chain. This class of cationic surfactants is probably the most studied model for investigating the effects of alkyl chain length and counterions on micellar properties. ${ }^{4-12}$ However, little is known about quaternary ammonium salts carrying a functional group in addition to the long alkyl chain on the quaternary ammonium. Such substitution should significantly affect headgroup hydration and counterion binding and thus allow the tuning of micelle properties. Examples for such compounds were synthesized by Swain et al. ${ }^{13}$ who prepared various alkyldimethylammonium bromides and iodides with the fourth group being an alkyl chain spacer terminated by a carboxylate, ester, amide, or nitrile group. These authors found that the melting points of almost all of these compounds were below $200{ }^{\circ} \mathrm{C}$, making their cations interesting as potential candidates for the preparation of surface-active ionic liquids (SAILs). ${ }^{14}$

It is well-known that the longer the alkyl chains of quaternary ammonium salts, the more toxic they are to living organisms, ${ }^{15}$ making many of these compounds useful in antibacterial or antifungal applications. However, there is a lack of systematic studies on systems containing 8-10 carbon atoms in the alkyl chain even for simple alkyltrimethylammonium halides. The exceptions are choline-based quaternary ammonium salts that have been recently studied ${ }^{16,17}$ and where Silva et al. determined the toxicity of mono- and dicationic cholinium-based ionic liquids. ${ }^{18}$

Received: November 29, 2018

Revised: February 11, 2019

Published: February 12, 2019 
Scheme 1. Structures of Studied Systems with a Decyl Alkyl Chain, R, and Different Functional Groups, X, and Their

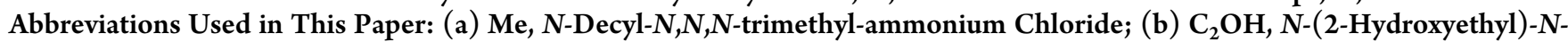
decyl- $\mathrm{N}, \mathrm{N}$-dimethylammonium Chloride; (c) $\mathrm{C}_{2} \mathrm{OMe}, \mathrm{N}$-(2-Methoxyethyl)- $\mathrm{N}$-decyl- $\mathrm{N}$, $\mathrm{N}$-dimethylammonium Chloride; (d) $\mathrm{C}_{2} \mathrm{OC}_{2} \mathrm{OMe}, \mathrm{N}$-(2-(2-Methoxyethoxy)ethyl)- $\mathrm{N}$-decyl- $\mathrm{N}, \mathrm{N}$-dimethylammonium Chloride; (e) $\mathrm{C}_{2} \mathrm{OOEt}, \mathrm{N}$-(2-Ethoxy-2oxoethyl)- $N$-decyl- $N, N$-dimethylammonium Chloride

a)

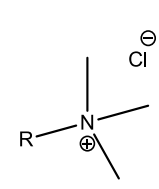

$\mathrm{Me}$ b)

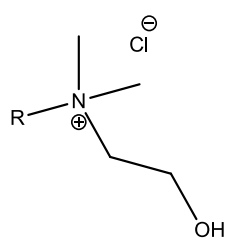

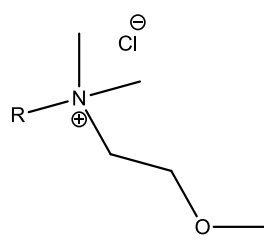

$\mathrm{C}_{2} \mathrm{OH}$
$\mathrm{C}_{2} \mathrm{OMe}$

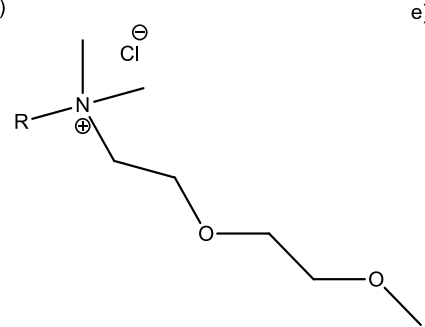

$\mathrm{C}_{2} \mathrm{OC}_{2} \mathrm{OMe}$

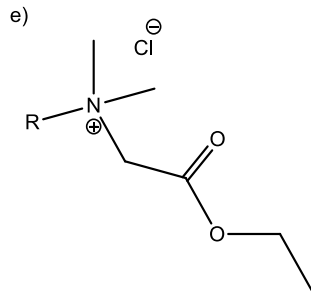

$\mathrm{C}_{2}$ OOEt
Thus, the aim of this present study was the synthesis and the characterization of selected $\mathrm{XRMe}_{2} \mathrm{~N}^{+} \mathrm{Cl}^{-}$compounds with a decyl moiety, $\mathrm{R}$, as the longest alkyl chain and an alcohol, ether, or ester group as a polar residue, $\mathrm{X}$ (Scheme 1). Because of the decyl alkyl chain, these compounds could be regarded as possible candidates for "green" and simultaneously SAILs. However, additional studies are required to assess the toxicity of these compounds. Additionally, the polar residues can make these micellar systems even more similar to proteins and thus more realistic models for the study of interactions in biological systems.

First, the thermal properties of the pure compounds were investigated by thermogravimetric analysis (TGA)/differential scanning calorimetry (DSC) experiments, followed by a thorough study of the effect of the functional group on the properties of aqueous solutions (density) and their micellization process in water.

Surprisingly, $N$-decyl- $N, N, N$-trimethylammonium chloride (commonly referred to as decyltrimethylammonium chloride-DeTAC) has rarely been the subject of investigations and hence was included in this work. The influence of the functional groups on the micellization behavior of functionalized decyldimethylammonium chlorides, $\mathrm{XC}_{10} \mathrm{Me}_{2} \mathrm{~N}^{+} \mathrm{Cl}^{-}$, (Scheme 1) in aqueous solutions was studied by isothermal titration calorimetry (ITC), one of the most powerful techniques for the thermodynamic characterization of aggregation processes.

ITC experiments were carried out in the temperature $(T)$ range between $278.15 \mathrm{~K}$ and $328.15 \mathrm{~K}$. The obtained experimental data were analyzed by an improved mass action model, considering micellization as a two-step process. ${ }^{19}$ In order to eliminate all the empirical constants appearing in the usually applied models, ${ }^{20,21}$ the state of the solutions in the syringe and in the titration cell was properly taken into account. By fitting the model equation to the experimental data, the corresponding standard thermodynamic parameters of micellization for both steps (enthalpy of micellization, $\Delta_{\mathrm{M}, 1} H^{\ominus}, \Delta_{\mathrm{M}, 2} H^{\ominus}$; Gibbs free energy of micellization, $\Delta_{\mathrm{M}, 1} G^{\ominus}$, $\Delta_{\mathrm{M}, 2} G^{\ominus}$; entropy of micellization, $\Delta_{\mathrm{M}, 1} S^{\ominus}, \Delta_{\mathrm{M}, 2} S^{\ominus}$; and heat capacity change upon micellization, $\left.\Delta_{\mathrm{M}, 1} c_{\mathrm{p}}^{\ominus}, \Delta_{\mathrm{M}, 2} c_{\mathrm{p}}^{\ominus}\right)$ were obtained. These results were discussed in terms of micelle size and changes in the hydration of the alkyl chains and the polar heads of the differently functionalized systems.

To get more insights into the hydration properties, effective hydration numbers were determined at $298.15 \mathrm{~K}$ by dielectric relaxation spectroscopy (DRS) in the frequency range $0.01 \leq$ $\nu / \mathrm{GHz} \leq 89$.

\section{EXPERIMENTAL SECTION}

Materials. Commercially available reagents and solvents were used as received from Sigma-Aldrich unless otherwise specified. Doubly distilled deionized water was obtained from a Millipore Milli-Q water purification system (Millipore, USA). ${ }^{1} \mathrm{H}$ NMR spectra were recorded on Bruker 300 or 400 or $500 \mathrm{MHz}$ NMR spectrometers and are available in Figures S1-S7 in the Supporting Information.

Synthetic Procedures. $\mathrm{C}_{10} \mathrm{Me}_{3} \mathrm{~N}^{+} \mathrm{Cl}^{-}$and $\left(\mathrm{C}_{2} \mathrm{OH}\right) \mathrm{C}_{10} \mathrm{Me}_{2} \mathrm{~N}^{+} \mathrm{Cl}^{-}$ were synthesized by the alkylation of the corresponding tertiary amine with chlorodecane. For the synthesis of the compounds with $\mathrm{C}_{2} \mathrm{OMe}$, $\mathrm{C}_{2} \mathrm{OC}_{2} \mathrm{OMe}$, and $\mathrm{C}_{2} \mathrm{OOEt}$ functional groups, first, $\mathrm{N}$-decyl- $\mathrm{N}, \mathrm{N}$ dimethylamine $\left(\mathrm{C}_{10} \mathrm{Me}_{2} \mathrm{~N}\right)$ was prepared by alkylation of dimethylamine with bromodecane, followed by its reaction with the appropriate functionalized chloro-substituted compound. The detailed procedures are described in the Supporting Information.

Thermal Analysis. TG measurements were performed on a Mettler Toledo TGA/DSC 1 Instrument, coupled to a Pfeiffer Vacuum ThermoStar mass spectrometer, in the temperature range from 25 to $400{ }^{\circ} \mathrm{C}$ under dynamic air flow $\left(100 \mathrm{~cm}^{3} \mathrm{~min}^{-1}\right)$ with a heating rate of $5 \mathrm{~K} \mathrm{~min}^{-1}$. Approximately $3 \mathrm{mg}$ of sample was weighed into a $150 \mu \mathrm{L}$ platinum crucible, and the baseline was subtracted. DSC measurements were performed separately on a Mettler Toledo DSC 1 instrument in aluminum crucibles under the same conditions.

Aqueous Solution Preparation. The synthesized samples (white solids) were stored in glass bottles. Solutions were prepared by weight, accounting for the amount of water in the solid samples as determined just before solution preparation by a Mettler Toledo DL38 Karl Fischer titrator.

Density Measurements. To enable the conversion between concentration scales and to calculate the apparent molar volumes of the micellar solutions in the concentration range of the experiments, the densities of all prepared solutions were measured at the $0.1 \mathrm{MPa}$ pressure in the temperature range from 278.15 to $328.15 \mathrm{~K}$ using a vibrating tube densimeter, Anton Paar DMA5000, with a stated reproducibility of $\pm 1 \cdot 10^{-3} \mathrm{~kg} \cdot \mathrm{m}^{-3}$.

Isothermal Titration Calorimetry. The heat changes associated with (de)micellization were measured using a VP-ITC microcalorimeter (MicroCal Inc., San Diego, CA, USA), where $1.00 \mathrm{~g}$ of distilled and degassed water was titrated with the surfactant solution added by a $300 \mu \mathrm{L}$ syringe. The surfactant concentrations were approximately $10-15$ times higher than their critical micellar concentration $(\mathrm{cmc})$. Successive aliquots of $2 \mu \mathrm{L}$ of the surfactant solution were injected at $10-15 \mathrm{~min}$ intervals by a motor-driven syringe into the titration cell containing the solution (solvent) while stirring at $300 \mathrm{rpm}$. For each system, experiments were carried out in $10 \mathrm{~K}$ steps between 278.15 and $328.15 \mathrm{~K}$. The area under the peak following each injection of the surfactant solution was obtained by integration of the raw signal (example in Figure S8 in the Supporting 
Table 1. Temperatures, $T$, and Enthalpies, $\Delta H$, of Phase Transition Together with the Melting Points, $T_{\mathrm{m}}$, and Enthalpies of Melting, $\Delta_{m} H$, of $\mathrm{XC}_{10} \mathrm{Me}_{2} \mathrm{~N}^{+} \mathrm{Cl}^{-}$Where X Represents $\mathrm{Me}, \mathrm{C}_{2} \mathrm{OH}, \mathrm{C}_{2} \mathrm{OMe}, \mathrm{C}_{2} \mathrm{OC}_{2} \mathrm{OMe}$, and $\mathrm{C}_{2} \mathrm{OOEt}$ Functional Groups ${ }^{a}$

\begin{tabular}{|c|c|c|c|c|c|}
\hline \multirow[b]{2}{*}{$\mathrm{X}$} & \multicolumn{2}{|c|}{ phase transition } & \multicolumn{2}{|c|}{ melting point } & \multirow[b]{2}{*}{$T_{\mathrm{dec}} /{ }^{\circ} \mathrm{C}$} \\
\hline & $\mathrm{T} /{ }^{\circ} \mathrm{C}$ & $\Delta H / \mathrm{kJ} \mathrm{mol}^{-1}$ & $T_{\mathrm{m}} /{ }^{\circ} \mathrm{C}$ & $\Delta_{\mathrm{m}} H / \mathrm{kJ} \mathrm{mol}^{-1}$ & \\
\hline $\mathrm{Me}$ & & & & & 210 \\
\hline $\mathrm{C}_{2} \mathrm{OH}$ & $55-85$ & 27.9 & $170-180$ & 3.6 & 190 \\
\hline $\mathrm{C}_{2} \mathrm{OMe}$ & & & $120-122$ & 41.4 & 165 \\
\hline $\mathrm{C}_{2} \mathrm{OC}_{2} \mathrm{OMe}$ & $93-102$ & 7.7 & $118-121$ & 28.4 & 165 \\
\hline $\mathrm{C}_{2} \mathrm{OOEt}$ & & & $93-98$ & 28.9 & 130 \\
\hline
\end{tabular}

Information), and it is proportional to the heat effect expressed per mole of the added surfactant. From the known starting mass of the water in the cell and the concentration and density of the stock solution in the syringe, the concentration after each addition was calculated first in moles of surfactant per $\mathrm{kg}$ of solution $(\mathrm{m}$, applied in the thermodynamic analysis) and then converted to molar concentration ( $c$, used in diagrams) by the help of the known concentration dependence of density.

Dielectric Relaxation Spectroscopy. The spectra of relative permittivity, $\varepsilon^{\prime}(\nu)$, and dielectric loss, $\varepsilon^{\prime \prime}(\nu)$, were recorded in the frequency range $0.01 \leq \nu / \mathrm{GHz} \leq 89$ at $(298.15 \pm 0.05) \mathrm{K}$. To obtain $\varepsilon^{\prime \prime}(\nu)$, the experimentally accessible total loss was corrected for $\mathrm{dc}$ conductivity, $\kappa$, and electrode polarization as described elsewhere. ${ }^{22} \mathrm{~A}$ waveguide interferometer ${ }^{23}$ was used for $\nu \geq 60 \mathrm{GHz}$, whereas a vector network analyzer (Agilent E8364B), in conjunction with two open-ended coaxial dielectric probes (Agilent 85070E-20 and $85070 \mathrm{E}-50)$ and a home-made coaxial-line cutoff cell, covered the remaining frequency range. ${ }^{24}$

The obtained spectra for $\varepsilon^{\prime}(\nu)$ and $\varepsilon^{\prime \prime}(\nu)$ were simultaneously fitted to various relaxation models following the criteria discussed in detail previously. ${ }^{25}$ Those for the $0.04 \mathrm{M}$ solutions of all surfactants were best described by a sum of five Debye equations $(n=5$; the 5D model)

$$
\varepsilon^{*}(\nu)=\varepsilon^{\prime}(\nu)-\mathrm{i} \varepsilon^{\prime \prime}(\nu)=\varepsilon_{\infty}+\sum_{j=1}^{n} \frac{S_{j}}{1+\mathrm{i} 2 \pi \nu \tau_{j}}
$$

whereas for solutions with $c \geq \mathrm{cmc}$, the superposition of $n=6$ Debye equations (the $6 \mathrm{D}$ model) produced slightly better fits and yielded results which better represent the state of these solutions (see below). In eq $1, \varepsilon_{\infty}$ is the high-frequency permittivity associated with intramolecular polarizability, $S_{j}$ is the amplitude of mode $j$, and $\tau_{j}$ is the associated relaxation time $\left(i^{2}=-1\right)$. As the highest-frequency mode ( $n=5$ resp. 6) peaks outside the covered frequency range, $\tau_{n}$ and $\varepsilon_{\infty}$ were fixed to their pure water values, $0.278 \mathrm{ps}$ and 3.52 , obtained from fitting data up to $2 \mathrm{THz},{ }^{26}$ to reduce the scatter of its amplitude, $S_{n}$.

\section{RESULTS AND DISCUSSION}

Thermal Stability. From the TG and DSC curves (Figure S9 in the Supporting Information), the phase transition temperature, melting point, and decomposition onset temperature as well as enthalpies of the phase transition and melting for all studied systems were estimated. All obtained data are listed in Table 1. Phase transition refers to the rearrangement of the crystal structure, while the melting point was confirmed visually. TG traces and associated mass spectrometry intensities for selected $\mathrm{m} / z$ values are compared in Figure S10 of the Supporting Information.

From Table 1, it is evident that introducing an ester group as a polar residue on the quaternary ammonium group significantly lowers the melting point. With $T_{\mathrm{m}}<100{ }^{\circ} \mathrm{C}$, $\mathrm{C}_{2} \mathrm{OOEt}$ can be regarded as a SAIL composed from a quaternary ammonium-based cation and a relatively small chloride anion. According to their melting points, the alcohol-, ether-, and polyether-functionalized compounds are molten salts with a relatively low $T_{\mathrm{m}}$. These results demonstrate that the appropriate functionalization with a polar residue on the quaternary ammonium group crucially changes the thermal properties of these systems, leading to the formation of molten salts or even SAILs. With shorter alkyl chains, these ionic liquids should have low toxicity and thus potentially represent "green" SAILs.

Volumetric Properties. The densities, $\rho(T, m)$, of the investigated aqueous solutions, recorded at concentrations of up to $m \approx 1.2 \mathrm{~mol} \mathrm{~kg}^{-1}$ of solution and temperatures between 278.15 and $328.15 \mathrm{~K}$, are gathered in Table S1 and Figure S11 of the Supporting Information. In the concentration range between 0 and $0.25 \mathrm{~mol} \mathrm{~kg}^{-1}$, a second-order polynomial was fitted to $\rho(m)$ at each temperature. The obtained parameters are given in Table S2 and Figure S12 of the Supporting Information together with the literature data for the density of water, $\rho_{\mathrm{H}_{2} \mathrm{O}}(T){ }^{27}$

According to Figure S11 and Table S1 of the Supporting Information, the density, $\rho$, of aqueous $\mathrm{C}_{10} \mathrm{Me}_{3} \mathrm{~N}^{+} \mathrm{Cl}^{-}$solution decreases with increasing concentration of the surfactant at all temperatures. This was also reported for some other aqueous solutions of cationic surfactants with the chloride counterion. ${ }^{28,29}$ On the other hand, the density of bromides is reported to increase with increasing concentration. ${ }^{30,31}$ Replacing a methyl group by a polar residue at the quaternary ammonium headgroup leads, at low temperatures, to a maximum in the density versus concentration plot (Figure S11). This unusual feature diminishes with increasing temperature. Thus, it appears that the unusual initial increase in $\rho$ could be ascribed to the formation of hydrogen bonds between the polar residue and water, leading to more "compact" structures and thus to an increase in density. As the concentration of the surfactant increases and the formation of the micelles starts, the formation of such polar residuewater hydrogen bonds becomes difficult because of steric constraints and therefore the density begins to decrease. Support for our hypothesis comes from the density measurements of aqueous alkali carboxylate solutions, ${ }^{19}$ where $\rho$ is always increasing with concentration and temperature because of the increasing number of anion-water hydrogen bonds.

From the density data, the corresponding apparent molar volumes, $V_{\phi}$, were calculated by

$$
V_{\phi}(T)=\frac{M}{\rho_{\mathrm{H}_{2} \mathrm{O}}(T)}-\frac{1}{b}\left(\frac{1}{\rho_{\mathrm{H}_{2} \mathrm{O}}(T)}-\frac{1}{\rho(T)}\right)
$$

where $M$ is the molar mass and $b$ is the surfactant molality (moles solute per kilogram of the solvent). Figure S13 shows 
the dependence of $V_{\phi}$ on $b$ for all studied systems at $298.15 \mathrm{~K}$. From these data, the apparent molar volume of free monomers, $V_{\phi}^{S}$, was estimated by extrapolation to $b=0$. From the molality dependence of the apparent molar volume, $V_{\phi}$, it is evident that above a concentration of $\sim 0.5 \mathrm{~mol} \mathrm{~kg}-1, V_{\phi}$ is almost constant. Therefore, the apparent molar volume of the surfactant in the micelles, $V_{\phi}^{\mathrm{M}}$, was obtained from the averaged values above $0.5 \mathrm{~mol} \mathrm{~kg}^{-1}$, yielding the values summarized in Table 2.

Table 2. Apparent Molar Volumes of the Free Monomers, $V_{\phi}^{\delta}$, and of the Surfactant in the Micelle, $V_{\phi}^{\mathrm{M}}$, Together with the Number of Water Molecules, Which May Be Packed around a Sphere of Volume $V_{\phi}^{S} / N_{\mathrm{A}}, n_{\mathrm{h}}^{0}(S)$ for Aqueous Solutions of $\mathrm{XC}_{10} \mathrm{Me}_{2} \mathrm{~N}^{+} \mathrm{Cl}^{-}$at 298.15 K; X Represents the Functional Groups $\mathrm{Me}, \mathrm{C}_{2} \mathrm{OH}, \mathrm{C}_{2} \mathrm{OMe}, \mathrm{C}_{2} \mathrm{OC}_{2} \mathrm{OMe}$, and $\mathrm{C}_{2} \mathrm{OOEt}^{a}$

\begin{tabular}{lccc}
\multicolumn{1}{c}{$\mathrm{X}$} & $V_{\phi}^{s b}$ & $V_{\phi}^{\mathrm{M} b}$ & $n_{\mathrm{h}}^{0}(S)$ \\
$\mathrm{Me}$ & 247.8 & 249.7 & 41.7 \\
$\mathrm{C}_{2} \mathrm{OH}$ & 263.6 & 270.1 & 42.9 \\
$\mathrm{C}_{2} \mathrm{OMe}$ & 285.1 & 289.0 & 44.5 \\
$\mathrm{C}_{2} \mathrm{OC}_{2} \mathrm{OMe}$ & 321.2 & 328.7 & 47.2 \\
$\mathrm{C}_{2} \mathrm{OOEt}$ & 302.4 & 309.9 & 45.8
\end{tabular}

${ }^{a}$ Units: $V_{\phi}^{S}$ and $V_{\phi}^{\mathrm{M}}$ in $\mathrm{cm}^{3} \mathrm{~mol}^{-1} \cdot{ }^{b}$ Uncertainty: \pm 2 .

Thus, we conclude that for larger $b$ values, the monomer concentration remains essentially constant and all the added surfactant ends up in micelles. In this region, the apparent molar volumes of free monomers, $V_{\phi}^{S}$, and monomers in the micelle, $V_{\phi}^{\mathrm{M}}$, are practically independent of the surfactant concentration.

Also included in Table 2 are the number of water molecules, $n_{\mathrm{h}}^{0}(S)$, which may be packed around a sphere of volume $V_{\phi}^{S} / N_{\mathrm{A}}$ (see the Supporting Information, p S16). ${ }^{32}$ This quantity can be regarded as a rough estimate for the number of $\mathrm{H}_{2} \mathrm{O}$ molecules, which can be accommodated in the first hydration shell of the free surfactant cations.

Thermodynamics of Micellization. Two-Step Micellization Model. In our previous work, a two-step micellization model was introduced. ${ }^{19}$ Formally, micellization may be regarded as a multistep process, involving a series of coupled equilibria with aggregation numbers, $i$, ranging from two to infinity ${ }^{33}$ and the specific thermodynamic parameters for each of them. However, for most of these $i$ values, the probability of finding such an aggregate is small and thus irrelevant for thermodynamic studies. Moreover, such a formal treatment of micellization would be highly impractical in the analysis of experimental data because of the excessive number of adjustable parameters. On the other hand, when micellization is less favorable, that is, the cmcs are large and predominantly aggregates with less than 20 monomers are formed, the usually assumed approximation describing micellization with one single equilibrium (the closed-association model ${ }^{34}$ ) fails to fit data well over a wide temperature range and at higher concentrations. This observation can be ascribed to the fact that the most probable aggregation number depends on the concentration and temperature. For the present systems, the simpler one-step model did not yield reasonable fits to the experimental ITC data, whereas this was achieved with the two-step model. However, it should be noted that the proposed two formation steps of this model cannot be considered as strictly separated processes with two well- defined populations of micelles having aggregation numbers $n_{1}$ and $n_{2}$, respectively. Instead, these characteristic numbers represent the range of micelle sizes in the given concentration and temperature ranges. A more detailed explanation can be found in our previous work; ${ }^{19}$ see also the Thermodynamic Parameters of Micellization and Aggregation Number section.

The two-step micellization model for the cationic surfactant can be represented with equilibria

$$
\begin{aligned}
& n_{1} \mathrm{C}^{+}+\beta n_{1} \mathrm{~A}^{-} \stackrel{K_{\mathrm{M}, 1}}{\rightleftarrows} \mathrm{C}_{n_{1}} \mathrm{~A}_{\beta n_{1}}(1-\beta) n_{1}+ \\
& n_{2} \mathrm{C}^{+}+\beta n_{2} \mathrm{~A}^{-} \stackrel{K_{\mathrm{M}, 2}}{\rightleftarrows} \mathrm{C}_{n_{2}} \mathrm{~A}_{\beta n_{2}}(1-\beta) n_{2}+
\end{aligned}
$$

where $\mathrm{C}^{+}$represents the free monomers of surfactant, $\mathrm{A}^{-}$ stands for the corresponding free counterions, and $\mathrm{C}_{n_{1}} \mathrm{~A}_{\beta n_{1}}{ }^{(1-\beta) n_{1}+}$ and $\mathrm{C}_{n_{2}} \mathrm{~A}_{\beta n_{2}}{ }^{(1-\beta) n_{2}+}$ stand for the micelles (M,1 and M,2) with aggregation numbers $n_{1}$ and $n_{2}$. The degree of counterion binding, $\beta$, is taken to be the same for M,1 and M,2. The equilibria between the involved species can be expressed by apparent equilibrium constants, $K_{\mathrm{M}, 1}$ and $K_{\mathrm{M}, 2}$,

$$
K_{\mathrm{M}, 1}=\frac{x_{\mathrm{M}, 1}}{x_{\mathrm{C}}^{{ }^{n_{1}} x_{\mathrm{A}}{ }^{\beta n_{1}}}} ; K_{\mathrm{M}, 2}=\frac{x_{\mathrm{M}, 2}}{x_{\mathrm{C}}{ }^{n_{2}} x_{\mathrm{A}}^{\beta n_{2}}}
$$

where activities are approximated to be equal to the molar fractions, $x_{i}$, of the involved species. The values for $K_{\mathrm{M}, 1}$ and $K_{\mathrm{M}, 2}$ are obtained from the corresponding standard Gibbs free energies of micellization, $\Delta_{\mathrm{M}, 1} G^{\ominus}$ and $\Delta_{\mathrm{M}, 2} G^{\ominus}$,

$$
\Delta_{\mathrm{M}, 1} G^{\ominus}=-\frac{R T}{n_{1}} \ln K_{\mathrm{M}, 1} ; \quad \Delta_{\mathrm{M}, 2} G^{\ominus}=-\frac{R T}{n_{2}} \ln K_{\mathrm{M}, 2}
$$

and determine the composition of each solution at a given total concentration of surfactant, $c$. For a detailed explanation, see the Supporting Information, p S19.

The enthalpy of solution can be written as

$$
\begin{aligned}
H= & n_{\mathrm{sol}} \bar{H}_{\mathrm{sol}}+n_{\mathrm{S}} \bar{H}_{\mathrm{CA}}^{\ominus}+n_{1} n_{\mathrm{M}, 1} \Delta_{\mathrm{M}, 1} H^{\ominus}+n_{2} n_{\mathrm{M}, 2} \Delta_{\mathrm{M}, 2} H^{\ominus} \\
& +2 R T^{2} B_{\mathrm{CA}}^{\prime} b_{\mathrm{C}} n_{\mathrm{C}}+R T^{2}\left[\left(1+(1-\beta) n_{1}\right) B_{\mathrm{MA}, 1}^{\prime} b_{\mathrm{M}, 1}\right. \\
& \left.n_{\mathrm{M}, 1}+\left(1+(1-\beta) n_{2}\right) B_{\mathrm{MA}, 2}^{\prime} b_{\mathrm{M}, 2} n_{\mathrm{M}, 2}\right]
\end{aligned}
$$

where $\Delta_{\mathrm{M}, 1} H^{\ominus}$ and $\Delta_{\mathrm{M}, 2} H^{\ominus}$ are enthalpies of micellization. Equation 7 is applicable to any calorimetric experimental method. The second part of the equation introduces a nonideal contribution, typical for solutions of ions (coefficients $B_{\mathrm{CA}}^{\prime}$, $B_{\mathrm{MA}, 1}^{\prime}$, and $\left.B_{\mathrm{MA}, 2}^{\prime}\right)$. Detailed derivation of the equation with a corresponding explanation for all of the symbols may be seen in the Supporting Information, p S20.

In ITC experiments, the measured heat changes

$$
\Delta H=\frac{q}{n_{\mathrm{S}, \text { stock }}}=\frac{H-H_{0}-H_{\text {stock }}}{n_{\mathrm{S}, \text { stock }}}
$$

are the result of three contributions, namely, the enthalpy of the stock solution, $H_{\text {stock, }}$ as well as the enthalpies of the solution in the cell before, $H_{0}$, and after addition, $H$, divided by the total amount of the surfactant added, $n_{\mathrm{S}, \text { stock }}$.

By combining eqs 7 and 8 , the final form of the model equation is given as 

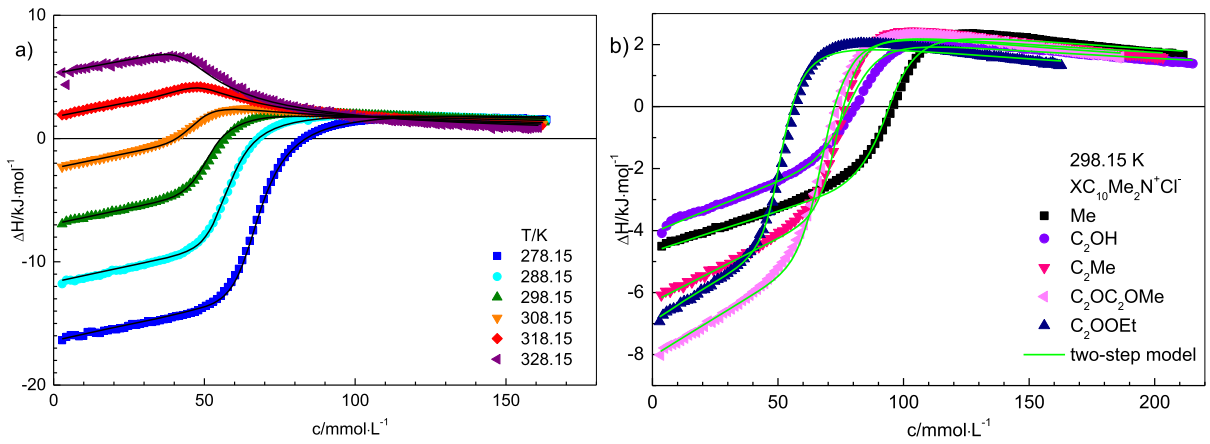

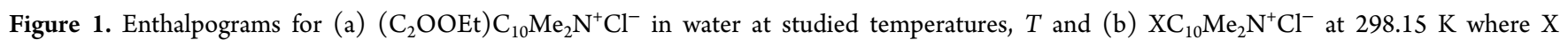
represents $\mathrm{Me}, \mathrm{C}_{2} \mathrm{OH}, \mathrm{C}_{2} \mathrm{OMe}, \mathrm{C}_{2} \mathrm{OC}_{2} \mathrm{OMe}$, and $\mathrm{C}_{2} \mathrm{OOEt}$ functional groups. Solid lines represent the fits with the two-step model, eq 9.

$$
\begin{aligned}
\Delta H= & \frac{\Delta n_{\mathrm{M}, 1}}{\Delta n} \Delta_{\mathrm{M}, 1} H^{\ominus}+\frac{\Delta n_{\mathrm{M}, 2}}{\Delta n} \Delta_{\mathrm{M}, 2} H^{\ominus} \\
& +\frac{R T^{2}}{n_{\mathrm{S}, \mathrm{stock}}} 2 B_{\mathrm{CA}}^{\prime}\left(\frac{n_{\mathrm{C}}{ }^{2}}{m_{\mathrm{sol}}}-\frac{n_{\mathrm{C}, 0}{ }^{2}}{m_{\mathrm{sol}, 0}}-\frac{n_{\mathrm{C}, \text { stock }}{ }^{2}}{m_{\mathrm{sol}, \mathrm{stock}}}\right) \\
& +\frac{R T^{2}}{n_{\mathrm{S}, \mathrm{stock}}} B_{\mathrm{MA}, 1}^{\prime}\left(1+(1-\beta) n_{1}\right)\left(\frac{n_{\mathrm{M}, 1}^{2}}{m_{\mathrm{sol}}}-\frac{n_{\mathrm{M}, 1,0}{ }^{2}}{m_{\mathrm{sol}, 0}}-\frac{n_{\mathrm{M}, 1, \text { stock }}{ }^{2}}{m_{\mathrm{sol}, \text { stock }}{ }^{2}}\right) \\
& +\frac{R T^{2}}{n_{\mathrm{S}, \mathrm{stock}}} B_{\mathrm{MA}, 2}^{\prime}\left(1+(1-\beta) n_{2}\right)\left(\frac{n_{\mathrm{M}, 2}{ }^{2}}{m_{\mathrm{sol}}}-\frac{n_{\mathrm{M}, 2,0}{ }^{2}}{m_{\mathrm{sol}, 0}}-\frac{n_{\mathrm{M}, 2, \text { stock }}{ }^{2}}{m_{\mathrm{sol}, \mathrm{stock}}}\right)
\end{aligned}
$$

where $\Delta n_{\mathrm{M}, 1} / \Delta n$ and $\Delta n_{\mathrm{M}, 2} / \Delta n$ are the changes in the amount of micelles upon addition. A detailed derivation with explanation of the symbols and indexes is given in the Supporting Information, p S21. The enthalpy change in eq 9 depends upon the amounts of micelles and free surfactant before and after the addition of the stock solution, their amounts in the stock solution itself, and the mass of solvent in all three solutions. A detailed derivation of the global fitting procedure of the model equation to the corresponding experimental curves at all the examined temperatures by considering the temperature dependence of the parameters is also shown in the Supporting Information, p S22. The value of the $\mathrm{cmc}$ for each of the investigated systems at a given temperature was estimated numerically from the inflection point of the line representing the dependence of $\Delta n_{\mathrm{M}, 2} / \Delta n$ on concentration.

Isothermal Titration Calorimetry. The dependence of the experimental heat of dilution, $\Delta H$, on surfactant concentration (enthalpogram) for the titration of $\left(\mathrm{C}_{2} \mathrm{OOEt}\right) \mathrm{C}_{10} \mathrm{Me}_{2} \mathrm{~N}^{+} \mathrm{Cl}^{-}$in water in the investigated temperature range is shown in Figure 1a. For all other studied systems, see Figure S14 of the Supporting Information. Figure $1 \mathrm{~b}$ shows the comparison of the enthalpograms of all the investigated surfactants at 298.15 K.

For evaluating the experimental ITC data, the two-step micellization model, ${ }^{19}$ eq 9, was applied. All parameters obtained by the fitting procedure are listed in Tables S3 and S4 in the Supporting Information. Figure 2 presents the corresponding thermodynamic parameters of micellization $\left(\Delta_{\mathrm{M}, 1} H^{\ominus}, \Delta_{\mathrm{M}, 2} H^{\ominus}, \Delta_{\mathrm{M}, 1} G^{\ominus}, \Delta_{\mathrm{M}, 2} G^{\ominus}, T \Delta_{\mathrm{M}, 1} S^{\ominus}, T \Delta_{\mathrm{M}, 2} S^{\ominus}\right)$ at $298.15 \mathrm{~K}$.

Thermodynamic Parameters of Micellization and Aggregation Number. For all investigated systems at $298.15 \mathrm{~K}$, the micellization process is endothermic for both steps and accompanied by a considerable increase in entropy, $\Delta_{\mathrm{M}, 1} S^{\ominus}$ and $\Delta_{\mathrm{M}, 2} S^{\ominus}$, so that the standard Gibbs free energies, $\Delta_{\mathrm{M}, 1} G^{\ominus}$ and $\Delta_{\mathrm{M}, 2} G^{\ominus}$, are negative (Figure 2 and Table S3). For both steps, the standard enthalpies of micellization, $\Delta_{\mathrm{M}, 1} H^{\ominus}$ and

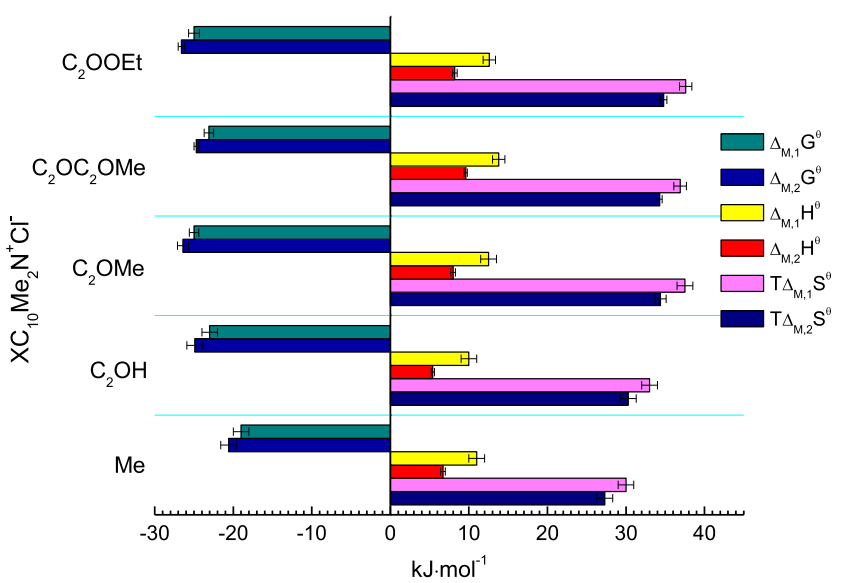

Figure 2. Thermodynamic parameters of micellization for the investigated systems in water at $298.15 \mathrm{~K}$ : standard enthalpies, $\Delta_{\mathrm{M}, 1} H^{\ominus}, \Delta_{\mathrm{M}, 2} H^{\ominus}$, Gibbs free energies, $\Delta_{\mathrm{M}, 1} G^{\ominus}, \Delta_{\mathrm{M}, 2} G^{\ominus}$, and entropy contributions, $T \Delta_{\mathrm{M}, 1} S^{\ominus}, T \Delta_{\mathrm{M}, 2} S^{\ominus}$, as obtained by the fitting procedure of the two-step model. Subscripts 1 and 2 refer to the first and second step of the model, according to eqs 3 and 4.

$\Delta_{\mathrm{M}, 2} H^{\ominus}$, decrease with temperature (Table S3). This is in line with previous thermodynamic studies of micellization, which revealed that this is an endothermic process at low temperatures but becomes exothermic at high temperatures. $7,11,12,20,21$ Usually, for cationic surfactants, the temperature where $\Delta_{\mathrm{M}} H^{\ominus}$ $=0$ is close to room temperature $(298 \pm 5 \mathrm{~K})$ but may depend on the counterion. ${ }^{35} \mathrm{~A}$ similar behavior was also found for alkali decyl- and alkali dodecylsulfates, ${ }^{36}$ whereas for carboxylates, the temperature where $\Delta_{\mathrm{M}} H^{\ominus}=0$ is distinctly shifted toward higher values $(\sim 320 \mathrm{~K}) .{ }^{19,37}$ For the present surfactants, this temperature was found to be $\sim 320 \mathrm{~K}$ for $\Delta_{\mathrm{M}, 1} H^{\ominus}$ and $\sim 310 \mathrm{~K}$ for $\Delta_{\mathrm{M}, 2} H^{\ominus}$, as can be seen from Table S3.

As already mentioned before, the aggregation numbers $n_{1}$ and $n_{2}$ of the applied two-step micellization model should only be regarded as characteristic numbers, which best represent the range of micelle sizes at the given concentration and temperature with smaller micelles $\left(n \approx n_{1}\right)$ dominating at low $c$ and larger entities $\left(n \approx n_{2}\right)$ at high $c$ and low $T$. In this formal treatment, each step has its defined Gibbs free energy, $\Delta_{\mathrm{M}, 1} G^{\ominus}$ and $\Delta_{\mathrm{M}, 2} G^{\ominus}$, and with eq 5, the apparent amount of micelles, $n_{\mathrm{M}, 1}$ and $n_{\mathrm{M}, 2}$, with sizes $n_{1}$ and $n_{2}$ can be calculated, yielding the average aggregation number, $n_{\text {avg }}$ as

$$
n_{\mathrm{avg}}=\frac{n_{1} n_{\mathrm{M}, 1}+n_{2} n_{\mathrm{M}, 2}}{n_{\mathrm{M}, 1}+n_{\mathrm{M}, 2}}
$$


Furthermore, from the thus accessible molar concentrations of the two micelle "species", $c_{\mathrm{M}, 1}$ and $c_{\mathrm{M}, 2}$, and the analytical surfactant concentration, $c$, the fraction of surfactant ions bound in micelles, $\alpha$,

$$
\alpha=\frac{n_{1} c_{\mathrm{M}, 1}+n_{2} c_{\mathrm{M}, 2}}{c}=1-\frac{c_{\mathrm{C}}}{c}
$$

is obtained; $c_{\mathrm{C}}$ is the molar concentration of free surfactant cations.

The resulting concentration and temperature dependences of $\alpha$ and $n_{\text {avg }}$ are presented in Figure 3 for $\left(\mathrm{C}_{2} \mathrm{OOEt}\right)$ -

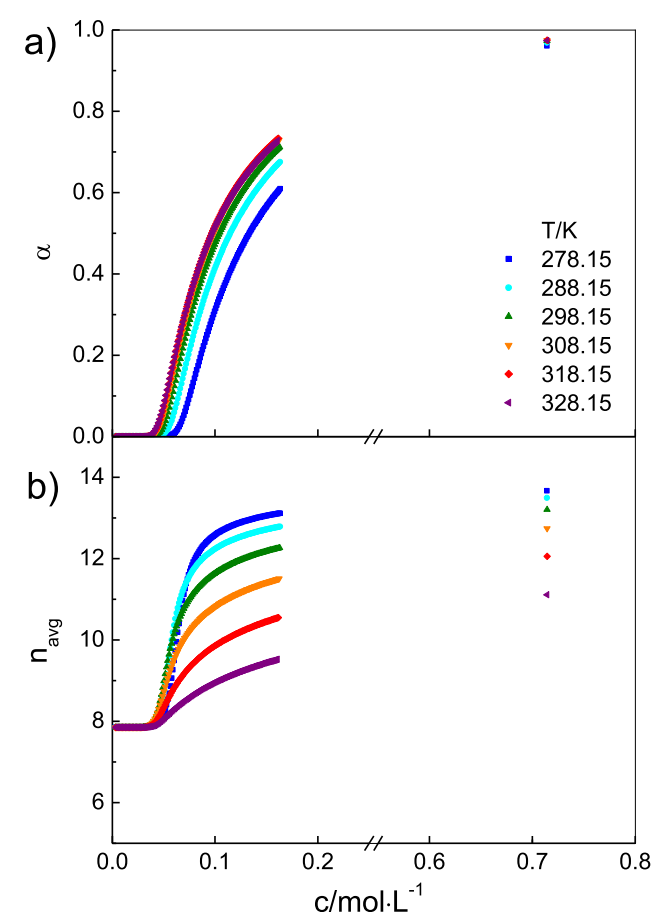

Figure 3. Concentration dependence of the (a) fraction of surfactant ions bound in micelles, $\alpha$, and (b) average aggregation number, $n_{\text {avg, }}$ for $\left(\mathrm{C}_{2} \mathrm{OOEt}\right) \mathrm{C}_{10} \mathrm{Me}_{2} \mathrm{~N}^{+} \mathrm{Cl}^{-}$at the investigated temperatures as estimated from eqs 11 and 10.

$\mathrm{C}_{10} \mathrm{Me}_{2} \mathrm{~N}^{+} \mathrm{Cl}^{-}$and in Figure $\mathrm{S} 15$ for all investigated systems. At concentrations significantly below cmc, $\alpha$ is negligible; thus, the calculated value of $n_{\text {avg }}$ is irrelevant, but above this threshold, the fraction of surfactant ions bound in micelles rapidly rises, reaching values close to unity at $\sim 1 \mathrm{~mol} \mathrm{~L}^{-1}$. Figures 5 and S19 reveal that around $\mathrm{cmc}$, micelle formation sets in with $n_{\text {avg }}=n_{1}$. With increasing $c$, the average aggregation numbers first rapidly increase, but from $c \approx 2 \mathrm{cmc}$ onward, the slope considerably reduces so that $n_{\text {avg }}$ only slowly approaches the plateau value, which is dependent on temperature and reaches $n_{2}$ at the lowest studied temperature. This trend becomes more obvious with increasing temperature so that at a given $c$ the average micelle size decreases with increasing $T$. To the best of our knowledge, no literature data are available for the substituted surfactants. However, the present value of $n_{2}=$ $24 \pm 2$ for $\mathrm{C}_{10} \mathrm{Me}_{3} \mathrm{~N}^{+} \mathrm{Cl}^{-}$is in excellent agreement with the aggregation number of $n_{\text {agg }}=26 \pm 3$ obtained by fluorescence quenching "at surfactant concentrations well above the $\mathrm{cmc}$ " ${ }^{38}$ This lends credit to the other $n_{2}$ values obtained in this investigation. Unfortunately, there are no other experimental methods that can precisely determine aggregation numbers at low surfactant concentrations. Furthermore, the temperature dependence of $n_{\text {avg }}$ (at high concentrations) is in the range of experimental errors of all known methods; thus, it is currently not possible to confirm the obtained temperature dependence by independent experiments.

Interestingly, $n_{1}$ has approximately the same value for all functional groups $\left(n_{1}=9 \pm 2\right)$, including the unsubstituted $\mathrm{C}_{10} \mathrm{Me}_{3} \mathrm{~N}^{+} \mathrm{Cl}^{-}$(Figure 4a and Table S4). This suggests that at

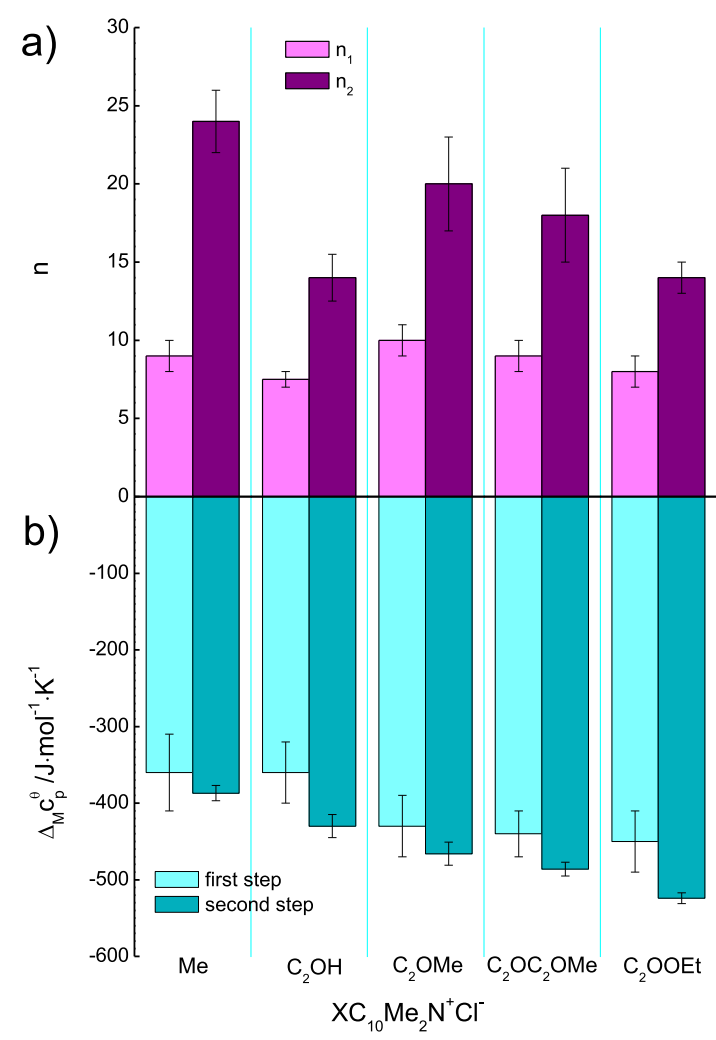

Figure 4. (a) Aggregation numbers, $n_{1}$ and $n_{2}$, and (b) heat capacities of micellization, $\Delta_{\mathrm{M}, 1} c_{\mathrm{p}}^{\ominus}$ and $\Delta_{\mathrm{M}, 2} c_{\mathrm{p}}^{\ominus}$, for both steps for the investigated systems.

the $\mathrm{cmc}$, the polar heads are so far apart that formation of these smaller micelles is not affected by the substituents. On the other hand, compared to the methyl group, $n_{2}$ is decreased for all functional groups. Thus, polar substituents at the headgroup decrease the number of molecules assembled in the micelle at high surfactant concentration, although steric effects cannot be the only reason for that, as the $\mathrm{C}_{2} \mathrm{OH}$ moiety yields the smallest $n_{2}$ value $(14 \pm 1.5)$

For both steps of the two-step model, the main driving force for micelle formation is the apparent disaffinity of water and the nonpolar (interacting) surfaces, known as the hydrophobic effect. $^{39}$ The parameters illustrating this are the large positive entropies of micellization, $\Delta_{\mathrm{M}, 1} S^{\ominus}$ and $\Delta_{\mathrm{M}, 2} S^{\ominus}$ (Table S3), as well as the heat capacities of micellization, $\Delta_{\mathrm{M}, 1} c_{\mathrm{p}}^{\ominus}$ and $\Delta_{\mathrm{M}, 2} c_{\mathrm{p}}^{\ominus}$, which are strongly negative for both steps (Figure $4 \mathrm{~b}$ and Table S4). These entropy and heat capacity changes can be ascribed to the dehydration of the nonpolar surfactant tails upon micelle formation. In fact, for all studied systems, the plot of $\Delta_{\mathrm{M}, 2} S^{\ominus}(298.15 \mathrm{~K})$ versus $\Delta_{\mathrm{M}, 2} c_{\mathrm{p}}^{\ominus}$ reveals a nearly linear dependence.

By modeling the micellization processes as a transfer of surfactant molecules into the micellar phase, the water accessible surface area (WASA) may be relevant for the estimation of the extent of dehydration of the nonpolar alkyl 
chains upon micellization. The heat capacity can be expressed in terms of the change of water accessible nonpolar and polar surface areas, derived from protein folding ${ }^{40}$

$$
\Delta_{\mathrm{M}} c_{\mathrm{p}}^{\ominus}=a \cdot \Delta A_{\mathrm{np}}+b \cdot \Delta A_{\mathrm{p}}
$$

where $\Delta A_{\mathrm{p}}$ stands for the loss of water accessible polar and $\Delta A_{\text {np }}$ for nonpolar surface area upon protein folding. For surfactants, it is usually assumed that the polar surface remains in contact with the water after micellization $\left.\left(\Delta A_{p}=0\right)\right)^{7,35,37}$ According to Richards, ${ }^{41-43}$ the WASA of a methylene group is 30 and $88 \AA^{2}$ for a methyl group. Thus, for the hydrophobic tails of all investigated $C_{10}$ surfactants, $\Delta A_{n p}$ should be very similar, $\sim 358 \AA^{2}$. In the literature, a variety of values for $a$ and $b$ coefficients may be found, ${ }^{40,44}$ but in many applications for proteins, ${ }^{44}$ they give very similar results. Assuming $a=(-1.34$ $\pm 0.33) \mathrm{J} \cdot \mathrm{mol}^{-1} \cdot \mathrm{K}^{-1} \cdot \AA^{-2}$ for this coefficient ${ }^{45}$ in eq 12 , the value of $\Delta_{\mathrm{M}} c_{\mathrm{p}}^{\ominus}\left(\mathrm{th}_{\mathrm{np}}\right)=(-479 \pm 118) \mathrm{J} \cdot \mathrm{mol}^{-1} \cdot \mathrm{K}^{-1}$ is obtained. This approach turned out to be successful for describing nonionic surfactants. ${ }^{46,47}$ For ionic surfactants, the approach served as estimation of the extent of the removed hydrophobic tail contact with water. ${ }^{19,20,35,48}$ It turned out that counterions $^{35}$ and the cation structure ${ }^{48}$ are also important.

From Figure 4 and Table S4, it is evident that for some of the investigated systems-with the same counterion and hydrophobic tail-the obtained values of $\Delta_{\mathrm{M}, 1} c_{\mathrm{p}}^{\ominus}$ and $\Delta_{\mathrm{M}, 2} c_{\mathrm{p}}^{\ominus}$ differ significantly from their theoretical value. On the other hand, the $\Delta_{\mathrm{M}, 2} c_{\mathrm{p}}^{\ominus}$ values for $\mathrm{C}_{2} \mathrm{OMe}, \mathrm{C}_{2} \mathrm{OC}_{2} \mathrm{OMe}$, and $\mathrm{C}_{2} \mathrm{OOEt}$ are very close to $\Delta_{\mathrm{M}} c_{\mathrm{p}}^{\ominus}\left(\mathrm{th}_{\mathrm{np}}\right)$, indicating that here the alkyl chain could be almost fully dehydrated upon micellization (in the second step). A possible reason for the difference in the values of $\Delta_{\mathrm{M}, 1} c_{\mathrm{p}}^{\ominus}$ and $\Delta_{\mathrm{M}, 2} c_{\mathrm{p}}^{\ominus}$ for some systems might be the increased or decreased hydration of the polar head upon micellization. Additionally, functional groups could be, and most likely are, oriented almost perpendicular to the alkyl chains, and this could contribute to the lower values of $n_{2}$ because of steric constraints.

For all studied surfactants, $\Delta_{\mathrm{M}, 1} H^{\ominus}>\Delta_{\mathrm{M}, 2} H^{\ominus}$ and $\Delta_{\mathrm{M}, 1} S^{\ominus}>$ $\Delta_{\mathrm{M}, 2} S^{\ominus}$ (Table S3). This suggests that for small micelles, the packing of the nonpolar tails in the core is not optimum. Thus, on insertion of further monomers, additional water molecules are released and better packed larger micelles are obtained.

Compared to the reference $(\mathrm{Me})$ and to the alcohol surfactant, enthalpies as well as entropies are considerably increased for $\mathrm{C}_{2} \mathrm{OMe}, \mathrm{C}_{2} \mathrm{OC}_{2} \mathrm{OMe}$, and $\mathrm{C}_{2} \mathrm{OOEt}$. All three have similar values for $\Delta_{\mathrm{M}, 1} H^{\ominus}\left(\sim 13 \mathrm{~kJ} \mathrm{~mol}^{-1}\right), \Delta_{\mathrm{M}, 1} S^{\ominus}(\sim 125$ $\left.\mathrm{J} \mathrm{K}^{-1} \mathrm{~mol}^{-1}\right)$, and $\Delta_{\mathrm{M}, 2} S^{\ominus}\left(\sim 115 \mathrm{~J} \mathrm{~K}^{-1} \mathrm{~mol}^{-1}\right) . \mathrm{C}_{2} \mathrm{OMe}$ and $\mathrm{C}_{2}$ OOEt have similar $\Delta_{\mathrm{M}, 2} H^{\ominus}$ values $\left(\sim 8 \mathrm{~kJ} \mathrm{~mol}^{-1}\right)$, while $\Delta_{\mathrm{M}, 2} \mathrm{H}^{\ominus}$ of $\mathrm{C}_{2} \mathrm{OC}_{2} \mathrm{OMe}\left(\sim 10 \mathrm{~kJ} \mathrm{~mol}^{-1}\right)$ is the largest. The larger enthalpies for the latter three compounds, as well as their entropy values, suggest that for both small and large micelles, either steric repulsion of the bulkier substituents becomes important or that upon micellization the polar headgroup is partly dehydrated. The thermodynamic data alone do not inform which effect is dominating. Interestingly, there is no significant difference in $n_{1}, n_{2}, \Delta_{\mathrm{M}, 1} S^{\ominus}, \Delta_{\mathrm{M}, 2} S^{\ominus}, \Delta_{\mathrm{M}, 1} c_{\mathrm{p}}^{\ominus}$, and $\Delta_{\mathrm{M}, 2} c_{\mathrm{p}}^{\ominus}$, between $\mathrm{C}_{2} \mathrm{OMe}$ and $\mathrm{C}_{2} \mathrm{OC}_{2} \mathrm{OMe}$, suggesting that the "extra" ethoxy group does not significantly affect the shape of micelles, besides decreasing the degree of counterion binding, and only slightly increases $\Delta_{\mathrm{M}, 2} H^{\ominus}$. On the other hand, in the case of $\mathrm{C}_{2} \mathrm{OH}$ and $\mathrm{C}_{2} \mathrm{OOEt}$, rather small micelles of similar size $\left(n_{2} \approx 14\right)$ are formed, despite significantly different values for all enthalpies, entropies, and heat capacities (Table S4).
This is discussed further in last part of the Results and Discussion.

Dielectric Relaxation Spectroscopy. Assignment of Modes. Typical spectra are shown in Figure 5 for the $0.2 \mathrm{M}$

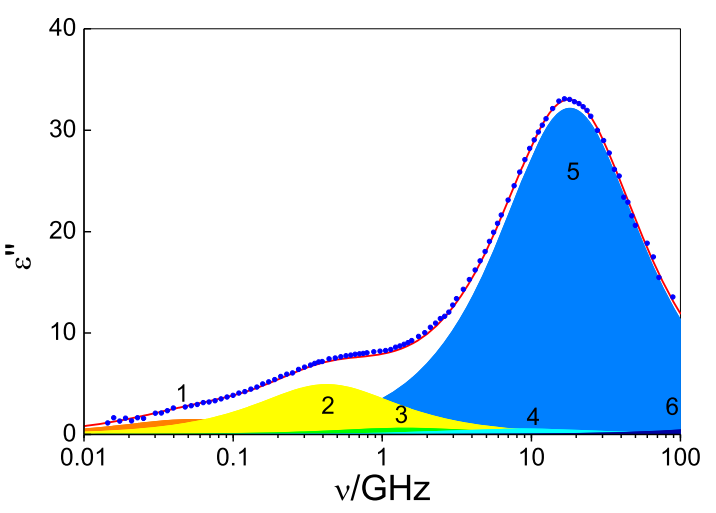

Figure 5. Dielectric loss, $\varepsilon^{\prime \prime}(\nu)$, spectrum $(\mathbf{0})$ of aqueous solutions of $0.2001 \mathrm{M}\left(\mathrm{C}_{2} \mathrm{OOEt}\right) \mathrm{C}_{10} \mathrm{Me}_{2} \mathrm{~N}^{+} \mathrm{Cl}^{-}$at $298.15 \mathrm{~K}$. The line shows the fit with the $6 \mathrm{D}$ model; the shaded areas indicate the contributions of the resolved modes $j=1, \ldots, 6$.

solution of $\left(\mathrm{C}_{2} \mathrm{OOEt}\right) \mathrm{C}_{10} \mathrm{Me}_{2} \mathrm{~N}^{+} \mathrm{Cl}^{-}$and in Figures $\mathrm{S} 16-\mathrm{S} 20$ of the Supporting Information for all studied systems at 0.04, 0.12 , and $0.2 \mathrm{M}$ as well as the spectra for the $0.7 \mathrm{M}$ solutions of $\mathrm{C}_{10} \mathrm{Me}_{3} \mathrm{~N}^{+} \mathrm{Cl}^{-}$and $\left(\mathrm{C}_{2} \mathrm{OOEt}\right) \mathrm{C}_{10} \mathrm{Me}_{2} \mathrm{~N}^{+} \mathrm{Cl}^{-}$. Because of the relatively complex synthesis and the rather large sample volumes required for DRS, $0.7 \mathrm{M}$ solutions could not be recorded for the other surfactants. The obtained parameters are summarized in Table S5 of the Supporting Information together with the associated densities and electrical conductivities determined in Regensburg as described elsewhere. ${ }^{22}$

For each of the studied concentrations, the spectra of all five studied surfactant solutions were rather similar in their appearance. Typical for aqueous solutions of ionic surfactants, ${ }^{49}$ the dielectric loss, $\varepsilon^{\prime \prime}(\nu)$, exhibited a dominating peak at $\sim 18 \mathrm{GHz}(j=4$ for $c<\mathrm{cmc} ; j=5$ otherwise $)$ associated with the solvent and because of the low surfactant concentrations, two weak contributions around $\sim 0.05 \mathrm{GHz}(j=1)$ and $\sim 0.5$ $\mathrm{GHz}(j=2)$ were observed. For solutions of charged colloids, including micelles, the latter relaxations are predicted by the theory of Grosse ${ }^{50}$ and associated, respectively, with fluctuations of the diffuse counterion cloud surrounding the micelle $(j=1)$ and the surface hopping of condensed counterions $(j=2)$. Because even nonassociating electrolytes, such as aqueous $\mathrm{NaCl}$, exhibit a weak ion-cloud relaxation around $0.1 \mathrm{GHz}$, ${ }^{51}$ finding such a contribution for the present surfactant systems already for the $0.04 \mathrm{M}$ solutions, that is well below the $\mathrm{cmc}$, was expected. Assignment to ion-cloud relaxation is supported by the observation that compared to the reference compound, $\mathrm{C}_{10} \mathrm{Me}_{3} \mathrm{~N}^{+} \mathrm{Cl}^{-}$, attachment of a functional moiety to the ammonium headgroup did not result in a significant change in the relaxation time, $\tau_{1}$. Additionally, the corresponding amplitude, $S_{1}$, remains rather similar in the concentration range between 0.04 and $0.2 \mathrm{M}$ for all studied systems (Table S5).

Moreover, the presence of a mode at $\sim 0.5 \mathrm{GHz}$ already for $c$ $<\mathrm{cmc}$ could be expected. Baar et al. discussed the simultaneous presence of octyltrimethylammonium bromide ion pairs and micelles formed by this surfactant, both showing a relaxation in the same frequency range. ${ }^{10}$ Alternatively to ionpair relaxation, it should be noted that for the present 
surfactant cations almost certainly their center of charge and their center of mass do not coincide. The reorientation of the resulting charge $\operatorname{arm}^{52}$ should also show up at similar frequencies in the dielectric spectrum.

In addition to the cooperative relaxation of the $\mathrm{H}$-bond network of water at $\sim 18 \mathrm{GHz}$ (parameters $S_{5}, \tau_{5}$ ), the weak mode $\left(S_{6}, \tau_{6}\right)$ at $\sim 500 \mathrm{GHz}$ associated with fast H-bond flipping ${ }^{26,53}$ could be unequivocally resolved. These two modes highlight different aspects in the continuous chain of events, leading to the reorientation of water dipoles. Thus, their combined amplitudes, $S_{\mathrm{b}}=S_{5}+S_{6}$, characterize the polarization associated with those $\mathrm{H}_{2} \mathrm{O}$ molecules in the solution, which behave, more or less, like pure water. As shown below, comparison of the DRS-detected concentration of bulklike water, calculated from $S_{\mathrm{b}}$, with the analytical $\mathrm{H}_{2} \mathrm{O}$ concentration yields the total hydration number (number of bound $\mathrm{H}_{2} \mathrm{O}$ molecules per equivalent of surfactant), $Z_{\mathrm{t}}$. It turned out that in general these $Z_{\mathrm{t}}$ bound water molecules can be subdivided into two fractions. The first, of number $Z_{\mathrm{ib}}$, is so strongly bound that they completely disappear from the covered dielectric spectrum (i.e., these dipoles are effectively frozen on the DRS time scale). The second fraction is only moderately retarded in their dynamics (retardation factor $r=$ $\tau_{3} / \tau_{4}$ for $c<\mathrm{cmc}$, otherwise $r=\tau_{4} / \tau_{5}$ ) so that it shows up as a separate "slow water" mode in the spectrum. ${ }^{54}$

Previous studies of tetraalkylammonium halide solutions ${ }^{55}$ and other small hydrophobic solutes ${ }^{54}$ identified the same slow water mode at $\sim 10 \mathrm{GHz}$ (relaxation times $\tau \approx 15-30 \mathrm{ps}$ ). Similar relaxation times were also observed for $\mathrm{C}_{x} \mathrm{Me}_{3} \mathrm{~N}^{+} \mathrm{X}^{-}$ surfactants, ${ }^{9,10,56}$ whereas for sodium dodecyl sulfate (SDS) solutions, this mode showed up at $\sim 2 \mathrm{GHz}(\sim 120 \mathrm{ps}) .{ }^{57}$ For all present spectra, a weak contribution between the slower surfactant-specific relaxation $\left(S_{2}, \tau_{2}\right)$ and the cooperative water mode $\left(S_{5}, \tau_{5}\right)$ is present. For $c<\mathrm{cmc}$, the associated relaxation time, $\tau_{4}$ in Table S5 and $\tau_{3}$ in Table S6, obtained with the 5D model is in the range of $14-33$ ps. However, for $c>\mathrm{cmc}$, the relaxation time jumped to values in the range of $\sim 50-150 \mathrm{ps}$ and scattered considerably, as did the corresponding amplitude (Table S6). Therefore, fits for these solutions were repeated assuming an additional contribution at $\sim 1 \mathrm{GHz}\left(S_{3}, \tau_{3}\right.$ in Table S5). Despite the small values resulting from these $6 \mathrm{D}$ fits for the amplitudes $S_{3}$ and $S_{4}$, rapid convergence was achieved and the fit quality (in terms of $\chi^{2}$, see ref 25 ) even slightly improved. On the basis of the data for $\operatorname{SDS}^{57}$ and tetraalkylammonium halides, ${ }^{55}$ we tentatively assign the mode associated with the thus obtained relaxation time of $\tau_{3}$ $\approx 80-200 \mathrm{ps}$ to retarded water molecules interacting with the micelles and that with $\tau_{4} \approx 14-40$ ps to $\mathrm{H}_{2} \mathrm{O}$ hydrating free monomers. However, note that water hydrating the hydrophilic functional groups of some of the present surfactants may have similar dynamics as a free monomer or in a micelle. ${ }^{58}$

Evaluation of the Relaxation Amplitudes. From the amplitude of bulklike water, $S_{\mathrm{b}}=S_{5}+S_{6}$ (corrected for kinetic depolarization with slip boundary conditions using the approach of Sega et al. ${ }^{59}$ ), and those of the two slow water modes, $S_{\mathrm{s}}^{\prime}=S_{3}$ and $S_{\mathrm{s}}^{\prime \prime}=S_{4}$, the corresponding DRS-detected solvent concentrations, $c_{\mathrm{b}}$ and $c_{s}^{\prime}$, $c_{s}^{\prime \prime}$, were calculated as described elsewhere. ${ }^{26}$ Comparison of $c_{\mathrm{b}}$ with the analytical water concentration, $c_{\mathrm{w}}$, then yields the total effective hydration number of the solute, $Z_{\mathrm{t}}=\left(c_{\mathrm{w}}-c_{\mathrm{b}}\right) / c$, that is, the number of $\mathrm{H}_{2} \mathrm{O}$ molecules per equivalent of solute, which differ in their dynamics from bulk water. The concentrations $c_{\mathrm{s}}^{\prime}$ and $c_{\mathrm{s}}^{\prime \prime}$ define the hydration numbers $Z_{\mathrm{s}}^{\prime}=c_{\mathrm{s}}^{\prime} / c$ and $Z_{\mathrm{s}}^{\prime \prime}=c_{\mathrm{s}}^{\prime \prime} / c$ of $\mathrm{H}_{2} \mathrm{O}$ molecules retarded in their dynamics by the factors $r^{\prime}=\tau_{3} / \tau_{5}$ and $r^{\prime \prime}=\tau_{4} / \tau_{5}$ because of moderate interactions with the solute in the micelle or with the surfactant monomer. It is important to note here that DRS detects hydration because of the different dynamics of the involved $\mathrm{H}_{2} \mathrm{O}$ molecules compared to the bulk. For the present surfactant systems, we were able to detect three different kinds of hydration water, either "frozen" (too slow to be detected in the covered frequency range, i.e., $r$ $\rightarrow \infty)$ or retarded by $r^{\prime}=\tau_{3} / \tau_{5}$ or $r^{\prime \prime}=\tau_{4} / \tau_{5}$. "Frozen" hydration water can be readily associated with hydrophilic hydration involving strongly attractive solute-solvent interactions, such as ion-dipole forces. Additionally, $r^{\prime}=\tau_{3} / \tau_{5}$ values of $10, \ldots, 25$ almost certainly reflect hydrophilic hydration. However, the rather small retardation of mode 4, $r^{\prime \prime}=\tau_{4} / \tau_{5} \approx 4$, is almost certainly produced by both hydrophilic and hydrophobic hydration, ${ }^{60}$ see the discussion below.

Surfactant Monomer Hydration. For the $0.04 \mathrm{M}$ solutions $Z_{\mathrm{s}}^{\prime}=0$ as no micelles are present and, within experimental uncertainty, $Z_{\mathrm{s}}^{\prime \prime} \approx Z_{\mathrm{t}}$. This means that all $Z_{\mathrm{t}}$ affected water molecules, which are obviously hydrating the surfactant cations because $Z_{\mathrm{t}}\left(\mathrm{Cl}^{-}\right)=Z_{\mathrm{s}}\left(\mathrm{Cl}^{-}\right)=0,{ }^{61}$ are only weakly slowed down by retardation factors of $r^{\prime \prime} \approx 2.2-3.9$, depending on the surfactant cation. While the two ethers and the ester show similar hydration numbers of $Z_{\mathrm{s}}^{\prime \prime} \approx 16, \ldots, 20$, this quantity drops to $\sim 7$ for $\mathrm{C}_{2} \mathrm{OH}$ but reaches $\sim 28$ for the $\mathrm{C}_{10} \mathrm{Me}_{3} \mathrm{~N}^{+}$ion (Figure S21). In all cases, the obtained $Z_{s}^{\prime \prime}$ values are significantly smaller than the numbers, $n_{\mathrm{h}}^{0}(S)$ (Table 2), of $\mathrm{H}_{2} \mathrm{O}$ molecules that can nominally be accommodated in the first hydration shell of the surfactant cation. Similar observations were made for $\mathrm{C}_{x} \mathrm{Me}_{3} \mathrm{~N}^{+} \mathrm{X}^{-9}$ and $\mathrm{Me}_{4} \mathrm{~N}^{+} \mathrm{X}^{-}{ }^{62}$ This may indicate that not all $\mathrm{H}_{2} \mathrm{O}$ molecules in the first hydration shell are equally slowed down. However, without reliable first-shell coordination numbers from simulations or scattering experiments to compare, one cannot exclude that the $n_{\mathrm{h}}^{0}(S)$ values are systematically too large. Unfortunately, experimental hydration numbers for the unsubstituted $\mathrm{C}_{10} \mathrm{Me}_{3} \mathrm{~N}^{+}$are scarce and completely lacking for the other surfactants of this study. From the hydrodynamic radius of $\mathrm{C}_{10} \mathrm{Me}_{3} \mathrm{~N}^{+}$, a hydration number of $\sim 23$ was estimated, ${ }^{9}$ which is in fair agreement with $Z_{\mathrm{s}}^{\prime \prime}=28$ for this cation. Also, the DRS value of $Z_{\mathrm{s}}^{\prime \prime} \approx 20$ for the shorter $\mathrm{C}_{8} \mathrm{Me}_{3} \mathrm{~N}^{+}$cation ${ }^{9}$ fits in. The monomer data of Figure S21, thus, indicate that a hydrophilic substituent, close to the charge center of the cation, partly compensates the hydrophobic slow down exerted by the methyl groups, possibly by acting as catalytic centers for solvent $\mathrm{H}$-bond switching. ${ }^{63}$

Micelle Hydration. It is reasonable to assume that for $c>$ $\mathrm{cmc}$, where the solutions contain a mixture of monomers and micelles, the resolved $\left(S_{4}, \tau_{4}\right)$ mode is also due to $\mathrm{H}_{2} \mathrm{O}$ molecules interacting with the monomers. This suggests that the additional $\left(S_{3}, \tau_{3}\right)$ mode found for these solutions and thus the corresponding hydration number $Z_{\mathrm{s}}^{\prime}$ can be assigned to the solvent interacting simultaneously with the charged surface of the micelles and counterions condensed thereon. ${ }^{49}$ With $r^{\prime} \approx$ $10, \ldots, 25$ for $c \approx 0.12$ and $0.2 \mathrm{M}$, the latter water molecules are considerably stronger bound than those hydrating surfactant monomers. This view is supported by the molecular dynamics (MD) simulations of $\mathrm{Pal}$ et $\mathrm{al}^{60}$ For a $\sim 0.4 \mathrm{M}$ aqueous $\mathrm{C}_{10} \mathrm{Me}_{3} \mathrm{~N}^{+} \mathrm{Br}^{-}$solution, they found a relaxation time of $164 \mathrm{ps}$ for water molecules in the interfacial layer of Me micelles. This value is in good agreement with the present $\tau_{3}$ values of $159 \mathrm{ps}$ at $0.12 \mathrm{M}$ and $133 \mathrm{ps}$ at $0.2 \mathrm{M}$ for $\mathrm{C}_{10} \mathrm{Me}_{3} \mathrm{~N}^{+} \mathrm{Cl}^{-}$(Table S5). 
Table 3. Total DRS Hydration Numbers, $Z_{v}$ and Corresponding Numbers $Z_{s}^{\prime}, Z_{s}^{\prime \prime}$ of Moderately Bound (Slow) Water Molecules per Equivalent of Solute Obtained from the Amplitudes $S_{3}$ and $S_{4}$; Fraction, $\alpha$, of Surfactant Cations Bound in Micelles and Corresponding Hydration Numbers of Slow Water, $Z_{\mathrm{s}}^{\mathrm{M}}$, and Total Water, $Z_{\mathrm{t}}^{\mathrm{M}}$, of Micelle-Bound Cations ${ }^{a}$

\begin{tabular}{|c|c|c|c|c|c|c|c|c|}
\hline $\mathrm{X}$ & $Z_{\mathrm{s}}^{\mathrm{S}}$ & $c$ & $Z_{\mathrm{s}}^{\prime}$ & $Z_{\mathrm{s}}^{\prime \prime}$ & $Z_{\mathrm{t}}$ & $\alpha$ & $Z_{\mathrm{s}}^{\mathrm{M}}$ & $Z_{\mathrm{t}}^{\mathrm{M}}$ \\
\hline \multirow[t]{3}{*}{$\mathrm{Me}$} & 27.9 & 0.1186 & 14 & 12 & 16 & 0.20 & 17 & 17 \\
\hline & & 0.1978 & 11 & 6.5 & 13 & 0.55 & 9.4 & 12 \\
\hline & & 0.6990 & 3.8 & 0.8 & 9.8 & 0.93 & 2.9 & 9.3 \\
\hline \multirow[t]{2}{*}{$\mathrm{C}_{2} \mathrm{OH}$} & 7.0 & 0.1195 & 5.3 & 0.4 & 5.2 & 0.30 & 2.4 & 2.4 \\
\hline & & 0.1981 & 7.8 & 2.6 & 8.6 & 0.60 & 13 & 14 \\
\hline \multirow[t]{2}{*}{$\mathrm{C}_{2} \mathrm{OMe}$} & 20.0 & 0.1196 & 12 & 1.9 & 6.5 & 0.37 & 2.4 & 2.4 \\
\hline & & 0.1994 & 7.2 & 6.2 & 13 & 0.66 & 9.9 & 19 \\
\hline \multirow[t]{2}{*}{$\mathrm{C}_{2} \mathrm{OC}_{2} \mathrm{OMe}$} & 15.8 & 0.1196 & 9.2 & 3.6 & 9.2 & 0.44 & 8.9 & 8.9 \\
\hline & & 0.1963 & 10 & 6.8 & 12 & 0.70 & 17 & 20 \\
\hline \multirow[t]{3}{*}{$\mathrm{C}_{2} \mathrm{OOEt}$} & 16.3 & 0.1196 & 7.9 & 1.7 & 7.6 & 0.58 & 4.8 & 4.8 \\
\hline & & 0.2001 & 4.6 & 4.1 & 10 & 0.75 & 6.1 & 14 \\
\hline & & 0.6979 & 3.7 & 0.7 & 10 & 0.97 & 4.0 & 11 \\
\hline
\end{tabular}

${ }^{a}$ Uncertainty: $Z_{\mathrm{s}}^{\mathrm{S}}: \pm 5, Z_{\mathrm{s}}^{\prime}, Z_{\mathrm{s}}^{\prime \prime}, Z_{\mathrm{t}}: \pm 3, \alpha: \pm 0.05$.

Interestingly, for the investigated $\sim 0.7 \mathrm{M}$ solutions of $\mathrm{C}_{10} \mathrm{Me}_{3} \mathrm{~N}^{+} \mathrm{Cl}$ and $\mathrm{C}_{2} \mathrm{OOEt}$, where $\sim 93-97 \%$ of the surfactant are bound in micelles, $r^{\prime}$ decreases to $\sim 4$ (because of lacking material, such measurements were not possible for the other surfactants). This may be a reflection of micelle-micelle interactions and, together with the limited experimental resolution then available, explain why for the $\mathrm{C}_{x} \mathrm{Me}_{3} \mathrm{~N}^{+} \mathrm{X}^{-}$ surfactants studied by Baar et al. ${ }^{9,10}$ only slow water relaxation times of $\sim 30$ ps were found.

From the amplitudes $S_{\mathrm{b}}, S_{3}$, and $S_{4}$ of the micelle-containing $0.12,0.2$, and $0.7 \mathrm{M}$ solutions, $Z_{\mathrm{t}}, Z_{\mathrm{s}}^{\prime}$, and $Z_{\mathrm{s}}^{\prime \prime}$ values were calculated as described above (Figure S21). Compared to the $0.04 \mathrm{M}$ samples containing only monomers, $Z_{\mathrm{t}}$ and $Z_{\mathrm{s}}^{\prime \prime}$ decreased considerably. However, these data, as well as $Z_{s}^{\prime}$, are of limited help, as they were obtained by normalizing the corresponding water concentrations, $c_{\mathrm{b}}, c_{\mathrm{s}}^{\prime}$, and $c_{\mathrm{s}}^{\prime \prime}$, to the total surfactant concentration. What is of interest are the corresponding numbers for the free cations, $Z_{s}^{S}$, and those bound in micelles, $Z_{\mathrm{s}}^{\mathrm{M}}$, which are related by the equation

$$
Z_{\mathrm{s}}^{\prime}+Z_{\mathrm{s}}^{\prime \prime}=\alpha Z_{\mathrm{s}}^{\mathrm{M}}+(1-\alpha) Z_{\mathrm{s}}^{\mathrm{S}}
$$

For the total hydration number, $Z_{\mathrm{v}}$, a similar relation holds. Thus, inserting the data for the micelle-free $0.04 \mathrm{M}$ solutions as values for $Z_{\mathrm{s}}^{\mathrm{S}}$ and the mole fractions, $\alpha$, of surfactant ions bound in micelles, obtained from the ITC measurements, yields the hydration numbers $Z_{\mathrm{s}}^{\mathrm{M}}$ of slow (retarded, $r^{\prime}=\tau_{3} / \tau_{5}$ ) $\mathrm{H}_{2} \mathrm{O}$ molecules per micelle-bound surfactant cation. Alternatively, the corresponding total number of bound water, $Z_{\mathrm{t}}^{\mathrm{M}}$, was calculated from the bulk-water amplitude.

However, only $Z_{\mathrm{s}}^{\prime}$ was taken into account in the calculation of $Z_{\mathrm{t}}^{\mathrm{M}}$. Thus, the data summarized in Table 3 have to be taken with a grain of salt. Because both slow water amplitudes are squeezed between the much larger micelle and bulk-water relaxations, their amplitudes $S_{3}$ and $S_{4}$ scatter considerably. As a side effect, in some cases, their sum is overestimated in the fit, whereas $S_{\mathrm{b}}$ is too small, that is, $c_{\mathrm{s}}^{\prime}+c_{\mathrm{s}}^{\prime \prime}>c_{\mathrm{w}}-c_{\mathrm{b}}$, which is unphysical. Also, the uncertainty of the free monomer values is very large $( \pm 5$, assuming an uncertainty of \pm 0.3 for all amplitudes of Table S5). Consequently, we abstain from a discussion of $Z_{\mathrm{t}}^{\mathrm{M}}$ and in particular of the number water molecules possibly "frozen" on the micelle surface, $Z_{\mathrm{ib}}^{\mathrm{M}}=Z_{\mathrm{t}}^{\mathrm{M}}-$ $Z_{\mathrm{s}}^{\mathrm{M}}$. Despite these problems, a look at the obtained hydration numbers $Z_{\mathrm{s}}^{\mathrm{M}}$ (Table 3) is nevertheless worthwhile. Except for $0.2 \mathrm{M}$ solutions of $\mathrm{C}_{2} \mathrm{OH}$ and $\mathrm{C}_{2} \mathrm{OC}_{2} \mathrm{OMe}$, all obtained $Z_{\mathrm{s}}^{\mathrm{M}}$ values are significantly smaller than the corresponding data for the free cations, $Z_{\mathrm{s}}^{\mathrm{S}}$. This result, pointing at surfactant dehydration on insertion into the micelle, seems reasonable as the micelle-embedded cations expose less hydrophobic surface to water.

For the unsubstituted compound $\left(\mathrm{C}_{10} \mathrm{Me}_{3} \mathrm{~N}^{+} \mathrm{Cl}^{-}\right), Z_{\mathrm{s}}^{\mathrm{M}}$ drops significantly from $\sim 17$ at $c=0.12 \mathrm{M}$ to $\sim 9$ at $0.2 \mathrm{M}$ and to $\sim 3$ at $c=0.7 \mathrm{M}$, but the value for $0.2 \mathrm{M}$ compares well to previous results for $\mathrm{C}_{8} \mathrm{Me}_{3} \mathrm{~N}^{+} \mathrm{Br}^{-}$(9.5), $\mathrm{C}_{12} \mathrm{Me}_{3} \mathrm{~N}^{+} \mathrm{Br}^{-}$(11.4), and $\mathrm{C}_{12} \mathrm{Me}_{3} \mathrm{~N}^{+} \mathrm{Cl}^{-}(14.2)$ at the same $c$. $^{9}$ Note that $\mathrm{Pal}$ et al. ${ }^{60}$ obtained in their MD simulations for $c=0.4 \mathrm{M}$ a coordination number of $25 \mathrm{H}_{2} \mathrm{O}$ molecules for the trimethylammonium groups of $\mathrm{C}_{10} \mathrm{Me}_{3} \mathrm{~N}^{+}$ions in micelles. This suggests that not all water molecules surrounding the headgroup are affected in their dynamics. On the other hand, at least for the $0.7 \mathrm{M}$ solution of $\mathrm{Me}$, the obtained $Z_{\mathrm{t}}^{\mathrm{M}}$ value is fairly reliable and significantly larger than $Z_{\mathrm{s}}^{\mathrm{M}}$. Therefore, we may conclude that with the increasing concentration of $\mathrm{C}_{10} \mathrm{Me}_{3} \mathrm{~N}^{+} \mathrm{Cl}^{-}$, only a part of the slow water hydrating the monomer of the surfactant is released to the bulk while the remaining $Z_{\mathrm{t}}^{\mathrm{M}}-\mathrm{Z}_{\mathrm{s}}^{\mathrm{M}} \approx 6 \mathrm{H}_{2} \mathrm{O}$ molecules per equivalent of surfactant in the micelle effectively "freeze". Even more, for other $\mathrm{C}_{x} \mathrm{Me}_{3} \mathrm{~N}^{+} \mathrm{X}^{-}$surfactants, values of $Z_{\mathrm{s}}^{\mathrm{M}} \approx 12 \pm 4$ were also found at $0.2 \mathrm{M}$. Thus, it appears that for tetraalkylammonium surfactants, the hydration number $Z_{\mathrm{s}}^{\mathrm{M}}$ is rather independent of the counterion or the alkyl chain length and is only slightly influenced by the functionalization of the headgroup. On the other hand, $\Delta_{M} c_{p}^{\ominus}$, which is ascribed to the dehydration of the nonpolar surfactant tails upon micelle formation, differs significantly among the different surfactants. Because there is obviously no correlation between $\Delta_{M} c_{\mathrm{p}}^{\ominus}$ and $Z_{\mathrm{s}}^{\mathrm{M}}$, we may conclude that the slowed down water is primarily hydrating the head group.

In contrast to the unsubstituted compound, the alcohol and the ethers showed that the number of retarded $\mathrm{H}_{2} \mathrm{O}$ molecules significantly increases when going from 0.12 to $0.2 \mathrm{M}$. This might reflect increasing $\mathrm{H}$-bond cooperativity for these substituents with increasing micelle size (Figure S15). Apparently, this is not the case for the ester as here $Z_{\mathrm{s}}^{\mathrm{M}}$ remains constant at low level $(\sim 5)$.

Estimation of Bare and Hydrated Micelle Volumes. Combining the results from the density measurements, ITC and DRS allow estimating the size of the micelles. From the apparent molar volume of the surfactant in the micelle, $V_{\phi}^{\mathrm{M}}$ (Table 2), corrected for $\mathrm{Cl}^{-}$ions $\left(17.83 \mathrm{~cm}^{3} \mathrm{~mol}^{-1}\right.$ at 298.15 
K), ${ }^{64}$ and the average aggregation number, $n_{\text {avg }}$ (Figure 3 ), the volume of the "bare" micelle, $V^{\mathrm{M}}$, can be obtained as

$$
V^{\mathrm{M}}=n_{\mathrm{avg}}\left(V_{\phi}^{\mathrm{M}}-(1-\beta) V_{\phi}\left(\mathrm{Cl}^{-}\right)\right) / N_{\mathrm{A}}
$$

The volume of the hydrated micelle, $V_{\text {hyd }}^{\mathrm{M}}$, is then given by

$$
V_{\text {hyd }}^{\mathrm{M}}=V^{\mathrm{M}}+n_{\text {avg }} Z_{\mathrm{s}}^{\mathrm{M}} V_{\mathrm{m}}\left(\mathrm{H}_{2} \mathrm{O}\right) / N_{\mathrm{A}}
$$

where $V_{\mathrm{m}}\left(\mathrm{H}_{2} \mathrm{O}\right)$ is the molar volume of water, $18.069 \mathrm{~cm}^{3}$ $\mathrm{mol}^{-1}$, at $298.15 \mathrm{~K}$. Assuming spherical micelles, the radii of bare, $r^{\mathrm{M}}$, and hydrated micelles, $r_{\text {hyd }}^{\mathrm{M}}$ gathered in Table 4 were obtained.

Table 4. Degree of Counterion Binding, $\beta$, Average Aggregation Number, $n_{\text {avg }}$, Volumes of the Bare Micelle, $V^{\mathrm{M}}$, and Hydrated Micelle, $V_{\text {hyd }}^{\mathrm{M}}$, and Corresponding Micelle

Radii, $r^{\mathrm{M}}$ and $r_{\text {hyd }}^{\mathrm{M}}$, for Aqueous Solutions of Concentrations, c, of $\mathrm{XC}_{10} \mathrm{Me}_{2} \mathrm{~N}^{+} \mathrm{Cl}^{-}$Surfactants at $298.15 \mathrm{~K}(\mathrm{X}=\mathrm{Me}$,

\begin{tabular}{|c|c|c|c|c|c|c|c|}
\hline $\mathrm{X}$ & $\beta$ & $c$ & $n_{\text {avg }}$ & $V^{\mathrm{M}}$ & $V_{\text {hyd }}^{\mathrm{M}}$ & $r^{\mathrm{M}}$ & $r_{\text {hyd }}^{\mathrm{M}}$ \\
\hline \multirow[t]{3}{*}{$\mathrm{Me}$} & 0.40 & 0.1186 & 16 & 6.3 & 14.5 & 1.15 & 1.51 \\
\hline & & 0.1978 & 20 & 7.9 & 13.6 & 1.24 & 1.48 \\
\hline & & 0.6990 & 22.2 & 8.8 & 10.7 & 1.28 & 1.37 \\
\hline \multirow[t]{2}{*}{$\mathrm{C}_{2} \mathrm{OH}$} & 0.68 & 0.1195 & 11 & 4.8 & 5.6 & 1.05 & 1.10 \\
\hline & & 0.1981 & 12 & 5.3 & 9.8 & 1.08 & 1.33 \\
\hline \multirow[t]{2}{*}{$\mathrm{C}_{2} \mathrm{OMe}$} & 0.72 & 0.1196 & 16 & 7.5 & 8.7 & 1.22 & 1.28 \\
\hline & & 0.1994 & 17.5 & 8.3 & 13.4 & 1.25 & 1.48 \\
\hline \multirow[t]{2}{*}{$\mathrm{C}_{2} \mathrm{OC}_{2} \mathrm{OMe}$} & 0.61 & 0.1196 & 13.5 & 7.2 & 10.8 & 1.20 & 1.37 \\
\hline & & 0.1963 & 15 & 8.0 & 15.9 & 1.24 & 1.56 \\
\hline \multirow[t]{3}{*}{$\mathrm{C}_{2} \mathrm{OOEt}$} & 0.67 & 0.1196 & 12 & 6.1 & 7.8 & 1.13 & 1.23 \\
\hline & & 0.2001 & 12.5 & 6.3 & 8.6 & 1.15 & 1.27 \\
\hline & & 0.6979 & 13.2 & 6.7 & 8.2 & 1.17 & 1.25 \\
\hline
\end{tabular}
$\mathrm{C}_{2} \mathrm{OH}, \mathrm{C}_{2} \mathrm{OMe}, \mathrm{C}_{2} \mathrm{OC}_{2} \mathrm{OMe}$, and $\left.\mathrm{C}_{2} \mathrm{OOEt}\right)^{a, b}$

Note that the actual radius of a micelle depends first on the definition of the "border" between the micelle and the bulk and second the extent to which the hydrated water is present inside the defined sphere is unknown. Therefore, the values of $r^{\mathrm{M}}$ and $r_{\text {hyd }}^{\mathrm{M}}$ estimated here are only two possible interpretations of $V^{\mathrm{M}}$ and $V_{\text {hyd }}^{\mathrm{M}}$. Nevertheless, the bare micelle radius as estimated for the $0.2 \mathrm{M}$ solution of $\mathrm{C}_{10} \mathrm{Me}_{3} \mathrm{~N}^{+} \mathrm{Cl}^{-}\left(r^{\mathrm{M}}=1.24 \mathrm{~nm}\right)$ is in excellent agreement with a recent $\mathrm{MD}$ simulation, yielding $r^{\mathrm{M}}$ $=1.230 \mathrm{~nm}$ with an all-atom description of the surfactant cation and $1.311 \mathrm{~nm}$ for a united-atom model. ${ }^{65}$ Neutron scattering experiments on $\mathrm{C}_{10} \mathrm{Me}_{3} \mathrm{~N}^{+} \mathrm{Br}^{-}$solutions yielded $\sim 1.0 \mathrm{~nm}$ for the radius of the hydrophobic core of the micelles plus $0.75 \mathrm{~nm}$ for the headgroups and their effective hydration shells. ${ }^{1}$ Thus, the resulting radius for the hydrated micelle, 1.75 $\mathrm{nm}$, is also comparable with the present value of $r_{\text {hyd }}^{\mathrm{M}}=1.48$ $\mathrm{nm}$. This suggests that our ITC determination of $n_{\text {avg }}$ is realistic.

For each of the 0.12 and $0.2 \mathrm{M}$ solutions of $\mathrm{C}_{2} \mathrm{OMe}$ and $\mathrm{C}_{2} \mathrm{OC}_{2} \mathrm{OMe}$, the $r^{\mathrm{M}}$ and $r_{\text {hyd }}^{\mathrm{M}}$ values of both surfactants are similar (Table 4). Apparently, the effect of the slightly smaller average aggregation number, $n_{\text {avg }}$ (Figure $\mathrm{S} 15$ ), of $\mathrm{C}_{2} \mathrm{OC}_{2} \mathrm{OMe}$ is canceled by the larger hydration number, $Z_{\mathrm{s}}^{\mathrm{M}}$ (Table 3 ), and the molar volume of this surfactant so that similar values for the thermodynamic parameters of micellization are obtained for both compounds (Table S3). In other words, the slightly smaller $n_{\text {avg }}$ of $\mathrm{C}_{2} \mathrm{OC}_{2} \mathrm{OMe}$ compared to that of $\mathrm{C}_{2} \mathrm{OMe}$ can be ascribed to the larger size of monomers and possibly steric constraints at micelle formation, resulting in similar values of $V^{\mathrm{M}}$. In addition, comparable values of $V_{\text {hyd }}^{\mathrm{M}}$ indicate that approximately the same amount of slowed down water per micelle is present for both compounds.

Thermodynamic Parameters in View of the Change of Hydration upon Micellization. The thermodynamic parameters determined by ITC with the two-step micellization model represent the difference between micelles and surfactant monomers in solution. Thus, they should not be compared to the hydration numbers obtained for the micelles, $Z_{\mathrm{s}}^{\mathrm{M}}$, but to the difference in hydration between micelles and monomers, $Z_{\mathrm{s}}^{\mathrm{M}}-Z_{\mathrm{s}}^{\mathrm{S}}$ (Figure 6). Because $Z_{\mathrm{s}}^{\mathrm{M}}-Z_{\mathrm{s}}^{\mathrm{S}}$ was determined at $0.2 \mathrm{M}$ (and $298.15 \mathrm{~K}$ ), the parameters for the second step in the twostep micellization model are relevant.

Let us first note that already the difference, $Z_{\mathrm{s}}^{\mathrm{M}}-Z_{\mathrm{s}}^{\mathrm{S}}$, reveals an interesting order: $\mathrm{Me}<\mathrm{C}_{2} \mathrm{OOEt} \approx \mathrm{C}_{2} \mathrm{OMe}<0<$ $\mathrm{C}_{2} \mathrm{OC}_{2} \mathrm{OMe}<\mathrm{C}_{2} \mathrm{OH}$. Thus, as one would expect, in the case

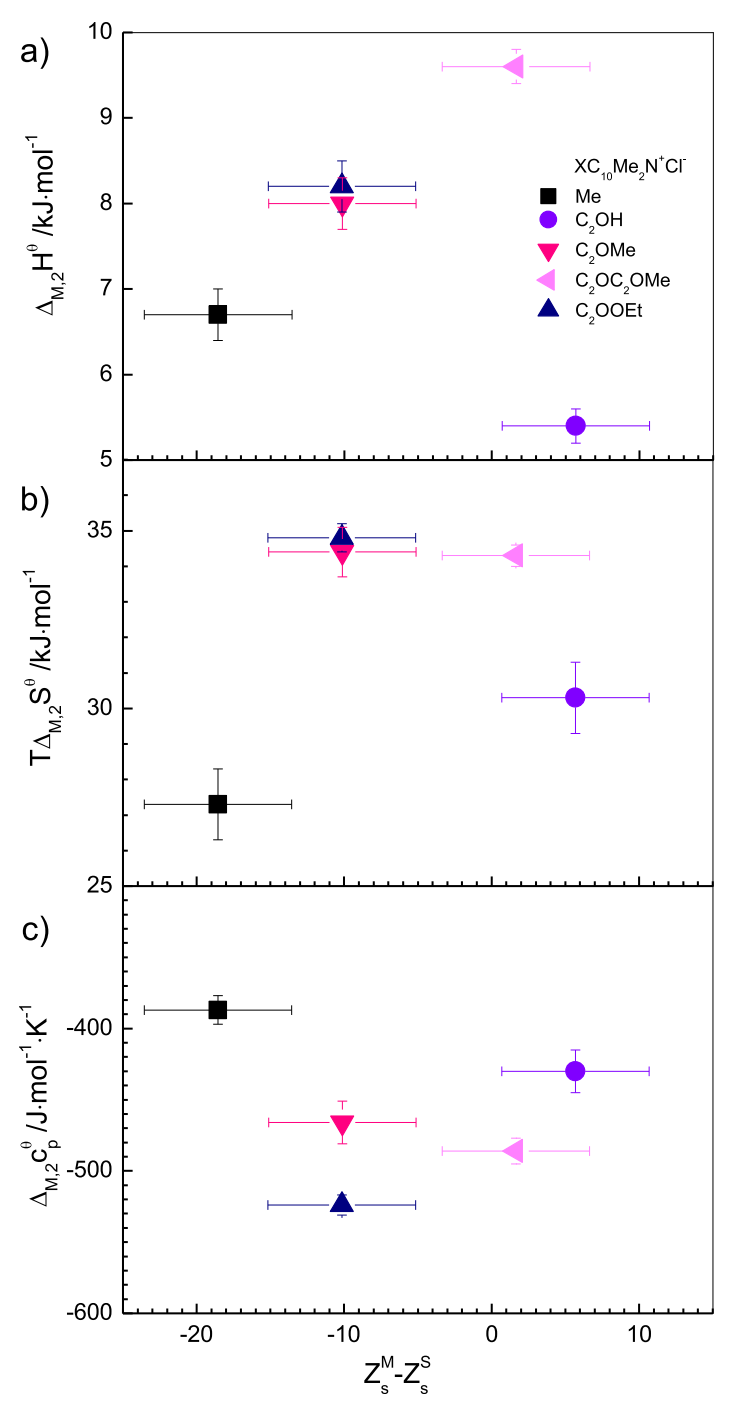

Figure 6. (a) Enthalpy, $\Delta_{\mathrm{M}, 2} H^{\ominus}$, at $298.15 \mathrm{~K}$, (b) entropy, $\Delta_{\mathrm{M}, 2} S^{\ominus}$, at $298.15 \mathrm{~K}$, and (c) heat capacity of micellization, $\Delta_{\mathrm{M}, 2} c_{\mathrm{p}}^{\ominus}$, of the second steps in the two-step micellization model for the investigated surfactants $\left(\mathrm{XC}_{10} \mathrm{Me}_{2} \mathrm{~N}^{+} \mathrm{Cl}^{-}\right.$, where $\mathrm{X}$ represents $\mathrm{Me}, \mathrm{C}_{2} \mathrm{OH}$, $\mathrm{C}_{2} \mathrm{OMe}, \mathrm{C}_{2} \mathrm{OC}_{2} \mathrm{OMe}$, and $\mathrm{C}_{2} \mathrm{OOEt}$ functional groups) as a function of the difference between the hydration numbers of surfactant ions in micelles and as monomers, $Z_{\mathrm{s}}^{\mathrm{M}}-Z_{\mathrm{s}}^{\mathrm{S}}$, as estimated here for $0.2 \mathrm{M}$ aqueous solutions. 
of the reference compound, the ester and the ether, the surfactant ion is more hydrated when it is free than when it is inserted in the micelle. However, with increasing polarity of the head group, the hydration of the inserted surfactant ion does not significantly change, whereas the hydration of the free monomer of the surfactant decreases (Table 3). It is possible that for the diether, the situation is inverted and certainly so for the alcohol.

The dehydration of the hydrophobic tail is an endothermic effect, and the release of water from the hydration shell of the hydrophobic tail to the bulk results in a positive entropy change. For the reference system, $\mathrm{C}_{10} \mathrm{Me}_{3} \mathrm{~N}^{+} \mathrm{Cl}^{-}$, the average aggregation numbers increase with raising concentration (Table 4, Figure S15), whereas micelle hydration is decreased (Table 3). This is in excellent agreement with the known properties of almost all water solutions of ionic solutes and a good indication that our experiments are correct and consistent. Unfortunately, hydration numbers for most of the other studied systems for the $0.12 \mathrm{M}$ solutions are at the limit of determination and probably underestimated, so we further discuss only the $0.2 \mathrm{M}$ solutions.

Dehydration is an endothermic process. Thus, the more the $\mathrm{H}_{2} \mathrm{O}$ molecules are removed from contact with the surfactant ion upon its insertion into the micelle, the larger, that is more positive, the $\Delta_{\mathrm{M}, 2} H^{\ominus}$ should be. However, with the exception of $\mathrm{C}_{2} \mathrm{OH}$, Figure 6a shows the opposite. This suggests that the dehydration of the alkyl chain cannot be the main reason for the observed differences in enthalpy change among studied surfactants. As discussed before, except for $\Delta_{\mathrm{M}, 2} H^{\ominus}, \mathrm{C}_{2} \mathrm{OMe}$, $\mathrm{C}_{2} \mathrm{OC}_{2} \mathrm{OMe}$, and $\mathrm{C}_{2} \mathrm{OOEt}$ exhibit comparable values for their corresponding thermodynamic parameters of micellization. Furthermore, $\mathrm{C}_{2} \mathrm{OMe}$ and $\mathrm{C}_{2} \mathrm{OC}_{2} \mathrm{OMe}$ have the same micelle size and a comparable amount of retarded water. Therefore, the observed enthalpy increase with increasing $Z_{\mathrm{s}}^{\mathrm{M}}-Z_{\mathrm{s}}^{\mathrm{S}}$ (Figure 6a) most likely reflects an increasing repulsion between headgroups because of their increasing size, that is, increasing the headgroup size increases steric constraints upon micelle formation. This is supported by the decreasing aggregation number in comparison to Me. The only exception is $\mathrm{C}_{2} \mathrm{OH}$ where the enthalpy change is even smaller than for Me. Because among the studied systems, the hydroxyl moiety of $\mathrm{C}_{2} \mathrm{OH}$ can form the strongest $\mathrm{H}$-bonds with water, effects of possible steric constraints to $\Delta_{\mathrm{M}, 2} H^{\ominus}$ are clearly overcompensated by increased hydration upon micellization.

The main driving force for the formation of micelles should be the apparent disaffinity of water and the nonpolar (interacting) surfaces known as hydrophobic effect. The thermodynamic parameter which illustrates this effect is the heat capacity of micellization, $\Delta_{M} c_{\mathrm{p}}^{\ominus}$, which is highly negative (Table S4 and Figures 4 and $6 \mathrm{c}$ ), and should be ascribed to the removal of water molecules from contact with the nonpolar surface area upon micelle formation. ${ }^{39}$

An inspection of Table 3 reveals clearly that the hydration of monomers of the investigated surfactants is very different and this must also influence the observed differences in $\Delta_{M} c_{\mathrm{p}}^{\ominus}$. The hydration of micelles is very similar among studied surfactants, except for $\mathrm{C}_{2} \mathrm{OOEt}$ where less retarded water was determined (approximately half). The experimental value of $\Delta_{\mathrm{M}, 2} c_{\mathrm{p}}^{\ominus}$ for $\mathrm{C}_{10} \mathrm{Me}_{3} \mathrm{~N}^{+} \mathrm{Cl}^{-}$is $-387 \mathrm{~J} \cdot \mathrm{mol}^{-1} \cdot \mathrm{K}^{-1}$, thus from the difference with $\Delta_{\mathrm{M}} c_{\mathrm{p}}^{\ominus}\left(\mathrm{th}_{\mathrm{np}}\right)$ it can be assumed that the theoretical estimate for $\Delta A_{n p}$ is too large and that the hydrophobic tail is still in contact with some water molecules after micellization. A similar argument could be made for $\mathrm{C}_{2} \mathrm{OH}\left(-430 \mathrm{~J} \cdot \mathrm{mol}^{-1}\right.$.
$\mathrm{K}^{-1}$ ); however, the difference is smaller and could also be due to changes in the hydrophilic headgroup hydration, $\Delta A_{\mathrm{p}}$, especially because the monomers are poorly hydrated $\left(Z_{s}^{\mathrm{S}}=7\right)$ and surfactant cations in micelles are more hydrated in comparison.

It is known that mixtures of water and alcohol (to which $\left(\mathrm{C}_{2} \mathrm{OH}\right) \mathrm{C}_{10} \mathrm{Me}_{2} \mathrm{~N}^{+} \mathrm{Cl}^{-}$systematically belongs) exhibit a particularly strange behavior: while methanol and ethanol are macroscopically miscible with water, their mixtures exhibit negative excess entropies of mixing. The dissolution of small amounts of 1-propanol in water leads to an evolution of heat, but the contrary is observed when small amounts of water are dissolved in this alcohol. The solubility of butanol in water is limited to a few per cent, above which there exists a gap of miscibility. Nevertheless, this dissolution remains remarkably exothermic. In contrast, the dissolution of small amounts of water in butanol absorbs heat from the surroundings. ${ }^{66}$ Different models for the structure of these mixtures have been proposed to address this behavior. These include an enhancement of the water hydrogen-bond network around the hydrophobic group of the alcohol or microscopic immiscibility because of clustering. Recently, mixtures of methanol, ethanol, and isopropanol with water were investigated by liquid microjet X-ray absorption spectroscopy on the oxygen Kedge, providing details of both the inter- and intramolecular structure. A significant enhancement of hydrogen bonding upon water addition was found, originating from the methanol and ethanol hydroxyl groups. These additional H-bond interactions strengthen liquid-liquid interactions, resulting in additional structural ordering and thus leading to a reduction in entropy and a negative enthalpy of mixing, consistent with existing thermodynamic data. In contrast, the spectra of the isopropanol-water mixtures exhibit an increase in the number of broken alcohol H-bonds for mixtures containing up to 0.5 mol fraction of water, an observation consistent with the existing enthalpy of mixing data, suggesting that the measured negative excess entropy is a result of clustering or microimmiscibility. ${ }^{67}$

Thus, for $\left(\mathrm{C}_{2} \mathrm{OH}\right) \mathrm{C}_{10} \mathrm{Me}_{2} \mathrm{~N}^{+} \mathrm{Cl}^{-}$, similar interactions with water can be assumed as for 1-butanol. The $-\mathrm{OH}$ group of the free monomers initiates additional ordering of the surrounding water molecules by building $\mathrm{H}$-bonds, leading to a reduction in entropy and enthalpy of the solution. Upon micellization, the surface of the micelle is more similar to the opposite situation of a concentrated alcohol solution in water. Thus, some of the additional $\mathrm{H}$-bonds of monomers with water are broken and the reduced entropy and enthalpy have to be compensated. The initial increase of density below $\mathrm{cmc}$ (Figure S11) supports the proposed additional ordering of the solution of monomers and gradual breaking of this increased order upon micelle formation is accompanied with the decrease of density above cmc. Thus, increased ordering because of the monomers could explain the increased entropy of micellization compared to Me. Nevertheless, enthalpy of micellization is still lower compared to $\mathrm{Me}$, most likely because of an increased hydration of the headgroup. The contribution of the increased hydration must be greater than the contribution of the increased steric constraints and breaking of the $\mathrm{H}$-bonds. The higher value of slowed down water molecules $\left(Z_{\mathrm{s}}^{\mathrm{M}}-Z_{\mathrm{s}}^{\mathrm{S}}=6\right)$ reflects this extensive additional hydration of the micelle surface, especially because $\Delta_{\mathrm{M}, 2} c_{\mathrm{p}}^{\ominus}$ indicates that the nonpolar alkyl chain is almost fully dehydrated. Thus, for $\mathrm{C}_{2} \mathrm{OH}$, the hydration of the polar head upon micellization is by far the strongest among all 
studied surfactants. Nevertheless, $\Delta_{\mathrm{M}, 2} c_{\mathrm{p}}^{\ominus}$ for $\mathrm{C}_{2} \mathrm{OH}$ is the largest among functionalized systems, thus the lowest value of $n_{2}$ could be due to space required for water molecules in the cavities between alkyl chains together with increased space required around the polar head.

While the $-\mathrm{OH}$ group can act as a donor and an acceptor of $\mathrm{H}$-bonds, ether and ester groups can only accept $\mathrm{H}$-bonds from water molecules. Nevertheless, a similar initial increase and subsequent decrease of density with concentration as for $\mathrm{C}_{2} \mathrm{OH}$ were measured for these three surfactants. This indicates that for these surfactants additional ordering of the water solution also occurs upon the addition of monomers. Thus, increased enthalpy and entropy upon micellization (Figure 6a,b) for $\mathrm{C}_{2} \mathrm{OMe}, \mathrm{C}_{2} \mathrm{OC}_{2} \mathrm{OMe}$, and $\mathrm{C}_{2} \mathrm{OOEt}$ could also be due to the breaking of the weak $\mathrm{H}$-bonds between free monomers and water. However, if this was the only contribution, the largest values of $\Delta_{\mathrm{M}, 2} S^{\ominus}$ would be expected for $\mathrm{C}_{2} \mathrm{OH}$ because of the strongest $\mathrm{H}$-bonding.

Values of $\Delta_{\mathrm{M}, 2} c_{\mathrm{p}}^{\ominus}$ for ethers $\left(\mathrm{C}_{2} \mathrm{OMe}\right.$ and $\left.\mathrm{C}_{2} \mathrm{OC}_{2} \mathrm{OMe}\right)$ are closer to the theoretical value of $\Delta_{\mathrm{M}} c_{\mathrm{p}}^{\ominus}\left(\mathrm{th}_{\mathrm{np}}\right)$, whereas for ester $\left(\mathrm{C}_{2} \mathrm{OOEt}\right)$ the value of $\Delta_{\mathrm{M}, 2} c_{\mathrm{p}}^{\ominus}$ is even more negative but within the uncertainty range. Therefore, in the same way as for $\mathrm{C}_{2} \mathrm{OH}$, the contribution of increased hydration of the headgroup upon micellization should probably be taken into account in eq 12. It can be assumed that upon micellization, most of the water molecules hydrating the surface of the surfactant ion are "relocated" from the alkyl chain to the surface of the micelle $\left(Z_{\mathrm{s}}^{\mathrm{M}}-Z_{\mathrm{s}}^{\mathrm{S}} \approx 0, \Delta_{\mathrm{M}, 2} c_{\mathrm{p}}^{\ominus} \approx \Delta_{\mathrm{M}} c_{\mathrm{p}}^{\ominus}\left(\mathrm{th}_{\mathrm{np}}\right)\right)$ for $\mathrm{C}_{2} \mathrm{OC}_{2} \mathrm{OMe}$, whereas for $\mathrm{C}_{2} \mathrm{OMe}$ and $\mathrm{C}_{2} \mathrm{OOEt}$, some water is additionally released to the bulk. The opposite is true for $\mathrm{C}_{2} \mathrm{OH}$, where upon micellization additional water from the bulk is required $\left(Z_{\mathrm{s}}^{\mathrm{M}}-Z_{\mathrm{s}}^{\mathrm{S}}>0\right)$. This probably reduces $\Delta_{\mathrm{M}, 2} S^{\ominus}$ compared to the large value expected for this surfactant because of strong $\mathrm{H}$-bonding.

\section{CONCLUSIONS}

Decyldimethylammonium chlorides, $\mathrm{XC}_{10} \mathrm{Me}_{2} \mathrm{~N}^{+} \mathrm{Cl}^{-}$, with a polar functional group, $\mathrm{X}=\mathrm{C}_{2} \mathrm{OH}, \mathrm{C}_{2} \mathrm{OMe}, \mathrm{C}_{2} \mathrm{OC}_{2} \mathrm{OMe}$, $\mathrm{C}_{2} \mathrm{OOEt}$ (Scheme 1), and decyltrimethylammonium chloride, $\mathrm{C}_{10} \mathrm{Me}_{3} \mathrm{~N}^{+} \mathrm{Cl}^{-}$, as a "reference" compound were synthesized and their thermal properties were determined, followed by an extensive study of their aqueous solutions.

The determined melting points and decomposition temperatures revealed that the functionalized surfactants had melting points below $200{ }^{\circ} \mathrm{C}$. The ester $\mathrm{C}_{2} \mathrm{OOEt}$, with a melting point below $100{ }^{\circ} \mathrm{C}$, can be even classified as an ionic liquid. Exchanging the relatively small chloride anion with a bulkier counterion would probably lower the melting points below room temperature.

The micellization process in an aqueous solution was investigated by density measurements, ITC, and dielectric spectroscopy. The thermodynamics of the micellization was studied by applying a two-step micellization model to the experimental ITC data. In addition to the thermodynamic parameters, the degree of counterion binding and the aggregation numbers for both steps were obtained. The substitution of one of the methyl groups by a polar functional group yielded micelles with lower aggregation numbers for the second step, which better describes concentrations above $c \approx 2$ times the $\mathrm{cmc}$, whereas the aggregation number for the first step (smaller aggregates), which better describes the aggregates formed at $\mathrm{cmc}$, is similar for all studied systems. The interpretation of the dielectric spectra with the appropriate model provided effective hydration numbers of free monomers, $Z_{\mathrm{s}}^{\mathrm{S}}$, and micelles, $Z_{\mathrm{s}}^{\mathrm{M}}$. Interestingly and counterintuitively, less water molecules are slowed down in their dynamics by the free cations bearing hydrophilic substituents compared to the mainly hydrophobic $\mathrm{C}_{10} \mathrm{Me}_{3} \mathrm{~N}^{+}$, indicating that water dynamics close to the hydrophilic moieties are similar to the bulk. According to the sequence $\mathrm{C}_{2} \mathrm{OH}<\mathrm{C}_{2} \mathrm{OC}_{2} \mathrm{OMe} \approx \mathrm{C}_{2} \mathrm{OOEt}<$ $\mathrm{C}_{2} \mathrm{OMe}<\mathrm{Me}$ for $Z_{\mathrm{s}}^{\mathrm{S}}$, the $\mathrm{OH}$ group, acting as both $\mathrm{H}$-bond donor and acceptor, is most efficient in breaking the (probably clathrate-like) hydration shell of the hydrophobic surfactant tail. The compounds with two oxygen atoms as $\mathrm{H}$-bond acceptors follow this pattern, whereas the monoether is the least efficient. This is in line with the Laage-Hynes model of hydration water dynamics. ${ }^{63}$ In contrast to the differences among the hydration of free monomers, upon micellization, approximately $12 \pm 4$ water molecules per headgroup are slowed down at the micelle surface for almost all studied surfactants. Except for $\mathrm{C}_{2} \mathrm{OOEt}$, where only approximately half this value was determined. This is in agreement with reported values for most single long-chain quaternary ammonium halides. Unfortunately, the obtained hydration numbers for the surfactant in the micelle, $Z_{\mathrm{s}}^{\mathrm{M}}$, are too widely scattered for a quantitative discussion.

The obtained thermodynamic parameters reflect the difference between free monomers and micelles, allowing a comparison to the difference in hydration numbers, $Z_{\mathrm{s}}^{\mathrm{M}}-$ $Z_{\mathrm{s}}^{\mathrm{S}}$. This revealed a complex balance between the steric constraints, H-bonding and the hydrophobic effect, which requires further studies.

Conversely, the estimated sizes of micelles and their radii, obtained by combining density measurements with ITC and DRS experimental data, are comparable for surfactants functionalized with a polar residue.

\section{ASSOCIATED CONTENT}

\section{S Supporting Information}

The Supporting Information is available free of charge on the ACS Publications website at DOI: 10.1021/acs.langmuir.8b03993.

Synthetic procedures, NMR spectra, thermodynamics of micellization, thermal analysis, densities of investigated systems, ITC, and DRS (PDF)

\section{AUTHOR INFORMATION}

\section{Corresponding Authors}

*E-mail: Richard.Buchner@chemie.uni-regensburg.de (R.B.).

*E-mail: marija.bester@fkkt.uni-lj.si (M.B.-R.).

ORCID ${ }^{\circ}$

Richard Buchner: 0000-0003-3029-1278

Marija Bešter-Rogač: 0000-0003-4284-5987

Notes

The authors declare no competing financial interest.

\section{ACKNOWLEDGMENTS}

This work was supported by the Slovenian Research Agency through grant no. P1-0201. Z.M. is grateful to Slovenian Research Agency for the position of young researcher enabling him the doctoral study and COST Action CM1206 for founding of the Short-Term Scientific Missions. The authors would like to acknowledge the contribution of the Deutscher Akademischer Austauschdienst in the framework of PPP 
Slovenia 2017 (project 57360142) and bilateral project between Germany and Slovenia (BI-DE/17-19-4). We thank Manuela A. Gilea, Martyn Earle, Miha Virant, and Janez Košmrlj for help with synthesis and Boštjan Žener, Nataša Čelan Korošin, and Romana Cerc Korošec for TG/DSC measurements.

\section{DEDICATION}

The paper is dedicated to the memory of Kenneth R. Seddon, who passed away in January 2018.

\section{REFERENCES}

(1) Hargreaves, R.; Bowron, D. T.; Edler, K. Atomistic Structure of a Micelle in Solution Determined by WideQ-Range Neutron Diffraction. J. Am. Chem. Soc. 2011, 133, 16524-16536.

(2) Long, J. A.; Rankin, B. M.; Ben-Amotz, D. Micelle Structure and Hydrophobic Hydration. J. Am. Chem. Soc. 2015, 137, 10809-10815.

(3) Lima, F. S.; Cuccovia, I. M.; Horinek, D.; Amaral, L. Q.; Riske, K. A.; Schreier, S.; Salinas, R. K.; Bastos, E. L.; Pires, P. A. R.; Bozelli, J. C., Jr.; Favaro, D. C.; Rodrigues, A. C. B.; Dias, L. G.; El Seoud, O. A.; Chaimovich, H. Effect of Counterions on the Shape, Hydration, and Degree of Order at the Interface of Cationic Micelles: The Triflate Case. Langmuir 2013, 29, 4193-4203.

(4) Milioto, S.; Causi, S.; Crisantino, R.; De Lisi, R. Thermodynamic studies of octyltrimethylammonium chloride in water. J. Therm. Anal. 1992, 38, 2693-2705.

(5) Kogej, K.; Škerjanc, J. Fluorescence and Conductivity Studies of Polyelectrolyte-Induced Aggregation of Alkyltrimethylammonium Bromides†. Langmuir 1999, 15, 4251-4258.

(6) Stodghill, S. P.; Smith, A. E.; O'Haver, J. H. Thermodynamics of Micellization and Adsorption of Three Alkyltrimethylammonium Bromides Using Isothermal Titration Calorimetry. Langmuir 2004, 20, 11387-11392.

(7) Kroflič, A.; Šarac, B.; Bešter-Rogač, M. Influence of the alkyl chain length, temperature, and added salt on the thermodynamics of micellization: Alkyltrimethylammonium chlorides in $\mathrm{NaCl}$ aqueous solutions. J. Chem. Thermodyn. 2011, 43, 1557-1563.

(8) Talhout, R.; Engberts, J. B. F. N. Self-Assembly in Mixtures of Sodium Alkyl Sulfates and Alkyltrimethylammonium Bromides: Aggregation Behavior and Catalytic Properties. Langmuir 1997, 13, 5001-5006.

(9) Baar, C.; Buchner, R.; Kunz, W. Dielectric Relaxation of Cationic Surfactants in Aqueous Solution. 1. Solvent Relaxation. J. Phys. Chem. B 2001, 105, 2906-2913.

(10) Baar, C.; Buchner, R.; Kunz, W. Dielectric Relaxation of Cationic Surfactants in Aqueous Solution. 2. Solute Relaxation. J. Phys. Chem. B 2001, 105, 2914-2922.

(11) Perger, T.-M.; Bešter-Rogač, M. Thermodynamics of micelle formation of alkyltrimethylammonium chlorides from high performance electric conductivity measurements. J. Colloid Interface Sci. 2007, $313,288-295$.

(12) Kroflič, A.; Šarac, B.; Bešter-Rogač, M. What affects the degree of micelle ionization: conductivity study of alkyltrimethylammonium chlorides. Acta Chim. Slov. 2012, 59, 564-570.

(13) Swain, A. P.; Braun, D. F.; Naegele, S. K. Synthesis of NAlkyldimethyl Derivatives of $\omega$-Amino Acids. J. Org. Chem. 1953, 18, 1087-1091.

(14) Greaves, T. L.; Drummond, C. J. Solvent nanostructure, the solvophobic effect and amphiphile self-assembly in ionic liquids. Chem. Soc. Rev. 2013, 42, 1096-1120.

(15) Zhang, C.; Cui, F.; Zeng, G.-m.; Jiang, M.; Yang, Z.-z.; Yu, Z.g.; Zhu, M.-y.; Shen, L.-q. Quaternary ammonium compounds (QACs): A review on occurrence, fate and toxicity in the environment. Sci. Total Environ. 2015, 518-519, 352-362.

(16) Jordan, D.; Tan, E.; Hegh, D. Synthesis, Characterization and Conductivity of Quaternary Nitrogen Surfactants Modified by the Addition of a Hydroxymethyl Substructure on the Head Group. J. Surfactants Deterg. 2012, 15, 587-592.
(17) Kharlamov, A. V.; Artyushin, O. I.; Bondarenko, N. A. Synthesis of some acyclic quaternary ammonium compounds. Alkylation of secondary and tertiary amines in a two-phase system. Russ. Chem. Bull. 2014, 63, 2445-2454.

(18) e Silva, F. A.; Siopa, F.; Figueiredo, B. F. H. T.; Gonçalves, A. M. M.; Pereira, J. L.; Gonçalves, F.; Coutinho, J. A. P.; Afonso, C. A. M.; Ventura, S. P. M. Sustainable design for environment-friendly mono and dicationic cholinium-based ionic liquids. Ecotoxicol. Environ. Saf. 2014, 108, 302-310.

(19) Medoš, Ž.; Bešter-Rogač, M. Two-Step Micellization Model: The Case of Long-Chain Carboxylates in Water. Langmuir 2017, 33, $7722-7731$

(20) Kroflič, A.; Šarac, B.; Bešter-Rogač, M. Thermodynamic Characterization of CHAPS Micellization Using Isothermal Titration Calorimetry: Temperature, Salt, and $\mathrm{pH}$ Dependence. Langmuir 2012, 28, 10363-10371.

(21) Šarac, B.; Mériguet, G.; Ancian, B.; Bešter-Rogač, M. Salicylate Isomer-Specific Effect on the Micellization of Dodecyltrimethylammonium Chloride: Large Effects from Small Changes. Langmuir 2013, $29,4460-4469$.

(22) Friesen, S.; Buchecker, T.; Cognigni, A.; Bica, K.; Buchner, R. Hydration and Counterion Binding of $\left[\mathrm{C}_{12} \mathrm{MIM}\right]$ Micelles. Langmuir 2017, 33, 9844-9856.

(23) Barthel, J.; Buchner, R.; Eberspächer, P.-N.; Münsterer, M.; Stauber, J.; Wurm, B. Dielectric relaxation spectroscopy of electrolyte solutions. Recent developments and prospects. J. Mol. Liq. 1998, 78, 83-109.

(24) Sonnleitner, T.; Turton, D. A.; Waselikowski, S.; Hunger, J.; Stoppa, A.; Walther, M.; Wynne, K.; Buchner, R. Dynamics of RTILs: A Comparative Dielectric and OKE Study. J. Mol. Liq. 2014, 192, 1925.

(25) Stoppa, A.; Nazet, A.; Buchner, R.; Thoman, A.; Walther, M. Dielectric Response and Collective Dynamics of Acetonitrile. J. Mol. Liq. 2015, 212, 963-968.

(26) Eiberweiser, A.; Nazet, A.; Hefter, G.; Buchner, R. Ion Hydration and Association in Aqueous Potassium Phosphate Solutions. J. Phys. Chem. B 2015, 119, 5270-5281.

(27) Herington, E. F. G. Recommended reference materials for the realization of physical properties-density. Pure Appl. Chem. 1976, 45, $1-9$.

(28) Morini, M. A.; Minardi, R. M.; Schulz, P. C.; Puig, J. E.; Rodriguez, J. L. Partial molar volume of dodecyltrimethylammonium hydroxide in water and $\mathrm{NaOH}$ aqueous solutions. Colloid Polym. Sci. 1998, 276, 738-742.

(29) González-Pérez, A.; Czapkiewicz, J.; Prieto, G.; Rodríguez, J. R. Second critical micelle concentration of dodecyldimethylbenzylammonium chloride in aqueous solution at $25{ }^{\circ} \mathrm{C}$. Colloid Polym. Sci. 2003, 281, 1191-1195.

(30) Wang, J.; Wang, H.; Zhang, S.; Zhang, H.; Zhao, Y. Conductivities, Volumes, Fluorescence, and Aggregation Behavior of Ionic Liquids $\left[\mathrm{C}_{4} \mathrm{mim}\right]\left[\mathrm{BF}_{4}\right]$ and $\left[\mathrm{C}_{\mathrm{n}} \operatorname{mim}\right] \mathrm{Br}(n=4,6,8,10,12)$ in Aqueous Solutions. J. Phys. Chem. B 2007, 111, 6181-6188.

(31) Zhang, Z.; Wang, H.; Shen, W. Densities, Conductivities, and Aggregation Numbers of Aqueous Solutions of Quaternary Ammonium Surfactants with Hydroxyethyl Substituents in the Headgroups. J. Chem. Eng. Data 2013, 58, 2326-2338.

(32) Eriksson, P.-O.; Lindblom, G.; Burnell, E. E.; Tiddy, G. J. T. Influence of organic solutes on the self-diffusion of water as studied by nuclear magnetic resonance spectroscopy. J. Chem. Soc., Faraday Trans. 1 1988, 84, 3129-3139.

(33) Schreier, S.; Malheiros, S. V. P.; de Paula, E. Surface active drugs: self-association and interaction with membranes and surfactants. Physicochemical and biological aspects. Biochim. Biophys. Acta, Biomembr. 2000, 1508, 210-234.

(34) Evans, D. E.; Wennerström, H. The Colloidal Domain, 2nd ed.; Wiley-VCH: New York, 1999.

(35) Šarac, B.; Medoš, Ž.; Cognigni, A.; Bica, K.; Chen, L.-J.; BešterRogač, M. Thermodynamic Study for Micellization of Imidazolium 
Based Surface Active Ionic Liquids in Water: Effect of Alkyl Chain Length and Anions. Colloids Surf., A 2017, 532, 609-617.

(36) Ropers, M. H.; Czichocki, G.; Brezesinski, G. Counterion Effect on the Thermodynamics of Micellization of Alkyl Sulfates. J. Phys. Chem. B 2003, 107, 5281-5288.

(37) Medoš, Ž.; Bešter-Rogač, M. Thermodynamics of the micellization process of carboxylates: A conductivity study. J. Chem. Thermodyn. 2015, 83, 117-122.

(38) Roger, G. M.; Durand-Vidal, S.; Bernard, O.; Turq, P.; Perger, T.-M.; Bešter-Rogač, M. Interpretation of Conductivity Results from 5 to $45{ }^{\circ} \mathrm{C}$ on Three Micellar Systems below and above the CMC. J. Phys. Chem. B 2008, 112, 16529-16538.

(39) Király, Z.; Dekány, I. A thermometric titration study on the micelle formation of sodium decyl sulfate in water. J. Colloid Interface Sci. 2001, 242, 214-219.

(40) Prabhu, N. V.; Sharp, K. A. Heat Capacity in Proteins. Annu. Rev. Phys. Chem. 2005, 56, 521-548.

(41) Richards, F. M. The interpretation of protein structures: total volume, group volume distributions and packing density. J. Mol. Biol. 1974, 82, 1-14.

(42) Richards, F. M. Areas, Volumes, Packing, and Protein Structure. Annu. Rev. Biophys. Bioeng. 1977, 6, 151-176.

(43) Richards, F. M. Calculation of molecular volumes and areas for structures of known geometry. Methods Enzymol. 1985, 115, 440464.

(44) Loladze, V. V.; Ermolenko, D. N.; Makhatadze, G. I. Heat capacity changes upon burial of polar and nonpolar groups in proteins. Protein Sci. 2001, 10, 1343-1352.

(45) Spolar, R. S.; Livingstone, J. R.; Record, M. T., Jr. Use of liquid hydrocarbon and amide transfer data to estimate contributions to thermodynamic functions of protein folding from the removal of nonpolar and polar surface from water. Biochemistry 1992, 31, 39473955.

(46) Chen, L.-J.; Sheu, Y.-H.; Li, P.-J. Heat capacity changes accompanying micelle formation upon burial of hydrophobic tail of nonionic surfactants. J. Phys. Chem. B 2004, 108, 19096-19098.

(47) Kresheck, G. C. Isothermal titration calorimetry studies of neutral salt effects on the thermodynamics of micelle formation. $J$. Phys. Chem. B 2009, 113, 6732-6735.

(48) Čobanov, I.; Šarac, B.; Medoš, Ž.; Vraneš, M.; Gadžurić, S.; Zec, N.; Bešter-Rogač, M. Effect of cationic structure of surface active ionic liquids on their micellization: A thermodynamic study. J. Mol. Liq. 2018, 271, 437-442.

(49) Buchner, R.; Baar, C.; Fernandez, P.; Schrödle, S.; Kunz, W. Dielectric Spectroscopy of Micelle Hydration and Dynamics in Aqueous Ionic Surfactant Solutions. J. Mol. Liq. 2005, 118, 179-187.

(50) Grosse, C. Permittivity of a Suspension of Charged Spherical Particles in Electrolyte Solution. 2. Influence of the Surface Conductivity and Asymmetry of the Electrolyte on the Low- and High-Frequency Relaxations. J. Phys. Chem. 1988, 92, 3905-3910.

(51) Eiberweiser, A.; Buchner, R. Ion-pair or ion-cloud relaxation? On the origin of small-amplitude low-frequency relaxations of weakly associating aqueous electrolytes. J. Mol. Liq. 2012, 176, 52-59.

(52) Kobrak, M. N.; Li, H. Electrostatic interactions in ionic liquids: the dangers of dipole and dielectric descriptions. Phys. Chem. Chem. Phys. 2010, 12, 1922-1932.

(53) Fukasawa, T.; Sato, T.; Watanabe, J.; Hama, Y.; Kunz, W.; Buchner, R. Relation between dielectric and low-frequency Raman spectra of hydrogen-bond liquids. Phys. Rev. Lett. 2005, 95, 197802.

(54) Buchner, R.; Hefter, G. Interactions and Dynamics in Electrolyte Solutions by Dielectric Spectroscopy. Phys. Chem. Chem. Phys. 2009, 11, 8984-8999.

(55) Buchner, R.; Hölzl, C.; Stauber, J.; Barthel, J. Dielectric spectroscopy of ion-pairing and hydration in aqueous tetra-nalkylammonium halide solutionsElectronic supplementary information (ESI) available: Relaxation parameters and relevant solution properties. See http://www.rsc.org/suppdata/cp/b1/b110361j/. Phys. Chem. Chem. Phys. 2002, 4, 2169-2179.
(56) Lima, F. S.; Chaimovich, H.; Cuccovia, I. M.; Buchner, R. Dielectric Relaxation Spectroscopy Shows a Sparingly Hydrated Interface and Low Counterion Mobility in Triflate Micelles. Langmuir 2013, 29, 10037-10046.

(57) Fernandez, P.; Schrödle, S.; Buchner, R.; Kunz, W. Micelle and Solvent Relaxation in Aqueous Sodium Dodecylsulfate Solutions. ChemPhysChem 2003, 4, 1065-1072.

(58) Schrödle, S.; Hefter, G.; Kunz, W.; Buchner, R. Effects of the non-ionic surfactant $\mathrm{C}_{12} \mathrm{E}_{5}$ on the cooperative dynamics of water. Langmuir 2006, 22, 924-932.

(59) Sega, M.; Kantorovich, S.; Arnold, A. Kinetic dielectric decrement revisited: phenomenology of finite ion concentrations. Phys. Chem. Chem. Phys. 2015, 17, 130-133.

(60) Pal, S.; Bagchi, B.; Balasubramanian, S. Hydration Layer of a Cationic Micelle, $\mathrm{C}_{10} \mathrm{TAB}$ : Structure, Rigidity, Slow Reorientation, Hydrogen Bond Lifetime, and Solvation Dynamics. J. Phys. Chem. B 2005, 109, 12879-12890.

(61) Sega, M.; Kantorovich, S.; Arnold, A. Kinetic dielectric decrement revisited: phenomenology of finite ion concentrations. Phys. Chem. Chem. Phys. 2015, 17, 130-133.

(62) Moreno-Gómez, N.; Vargas, E. F.; Buchner, R. The Effect of Alkyl-chain Branching on the Hydration and Ion Association of Tetrabutylammonium Cations. J. Mol. Liq. 2017, 248, 586-594.

(63) Laage, D.; Stirnemann, G.; Sterpone, F.; Rey, R.; Hynes, J. T. Reorientation and Allied Dynamics in Water and Aqueous Solutions. Annu. Rev. Phys. Chem. 2011, 62, 395-416.

(64) Marcus, Y. The Standard Partial Molar Volumes of Ions in Solution. Part 4. Ionic Volumes in Water at $0-100{ }^{\circ} \mathrm{C}$. J. Phys. Chem. B 2009, 113, 10285-10291.

(65) Jorge, M. Molecular Dynamics Simulation of Self-Assembly ofn-Decyltrimethylammonium Bromide Micelles. Langmuir 2008, 24, 5714-5725.

(66) Peeters, D.; Huyskens, P. Endothermicity or exothermicity of water/alcohol mixtures. J. Mol. Struct. 1993, 300, 539-550.

(67) Lam, R. K.; Smith, J. W.; Saykally, R. J. Communication: Hydrogen bonding interactions in water-alcohol mixtures from X-ray absorption spectroscopy. J. Chem. Phys. 2016, 144, 191103. 